Review

\title{
Advances in cellular immunotherapy: understanding and preventing T-cell dysfunction
}

\author{
Valérie Janelle ${ }^{1, *}$ and Jean-Sébastien Delisle 1,2,3 \\ 1 Centre de recherche de l’Hôpital Maisonneuve-Rosemont, Montréal, Québec, Canada. \\ 2 Division of Hematology-Oncology, Hôpital Maisonneuve-Rosemont, Montréal, Québec, Canada. \\ 3 Department of Medicine, Université de Montréal, Montréal, Québec, Canada. \\ * Correspondence to VJ: valerie.janelle@umontreal.ca
}

\begin{abstract}
Over the last decades, cellular immunotherapy has revealed its curative potential. However, inherent physiological characteristics of immune cells can limit the potency of this approach. Best defined in T cells, dysfunction associated with terminal differentiation, exhaustion, senescence, and activation-induced cell death, undermine adoptive cell therapies. In this review, we concentrate on how the multiple mechanisms that articulate the various forms of immune dysfunction impact cellular therapies primarily involving conventional $\mathrm{T}$ cells, but also other lymphoid subtypes, in addition to the various strategies put in place to circumvent these effects. The repercussions of immune cell dysfunction across the full life cycle of cell therapy, from the source material, during manufacturing, and after adoptive transfer are discussed. Applicable to cellular products prepared from native and unmodified immune cells, as well as genetically engineered therapeutics, the understanding and potential modulation of dysfunctional features is key to the development of improved cellular immunotherapies.
\end{abstract}

Keywords: T cells, chimeric antigen receptor, transgenic T-cell receptor, tumor-infiltrating lymphocytes, exhaustion, terminal differentiation, senescence, apoptosis, adoptive cell transfer, immunotherapy.

\section{Introduction}

Adoptive cell immunotherapy (ACT) is a promising approach to treat a variety of pathological states including infections, as well as both solid and hematologic cancers. Immune cells in ACT can be harvested from tumor resection/biopsy, from the patient's own blood or donated by a full or partially human leukocyte antigen (HLA)-matched healthy donor. These cells will then be injected to the patient after minimal or more extensive ex vivo manipulations. The oldest and arguably still one of the most effective form of $\mathrm{ACT}$ is allogeneic hematopoietic cell transplantation, which most often requires only minimal cell handling and primarily leverages immunogenetic disparities between donor and recipient to treat hematopoietic cancers [1]. Such a rather prosaic form of ACT is associated with several shortcomings including unpredictable therapeutic effect and immune complications in the form of graft-versus-host disease (GVHD). Increasingly however, $e x$ vivo procedures are used to both enhance "on-target" effects on cancer or infected cells and minimize immune complications. This review will emphasize these latter forms of immunotherapy that hinge on advanced ex vivo cellular manipulation procedures. Genetic cellular engineering has also been implemented to achieve optimal cell targeting and minimize off-target effects. In most cases, the manufacturing of therapeutic T-cell products requires T-cell stimulation and expansion which may be conducive to the acquisition of dysfunctional features [2]. Similarly, continuous and/or chronic antigen encounters after patients infusion will often further accentuate T-cell dysfunctionality. Thus, understanding the physiology behind the various T-cell dysfunctional states is fundamental to the design of optimal ACT protocols. 
T-cell dysfunction is not inherently good nor bad, but must be considered as a central aspect of T-cell physiology. In the natural course of an immune response, a high number of $\mathrm{T}$ cells will be rapidly generated to eliminate the foreign (most often microbial) antigens. After resolution of the threat, a contraction in the total number of $\mathrm{T}$ cells limits the risks associated with a sustained inflammatory response and restores homeostasis. Some lymphocytes will be converted into long term memory cells to protect the organism against future exposure to the same microorganism. During this process, T-cell differentiation will be governed by the strength as well as the duration of the stimulation received by the T cell [3]. The T-cell receptor (TCR) complex, composed of TCR $\alpha / \beta$ chains and responsible for the antigenic recognition, will co-operate with a CD3 molecule responsible for transducing the activation signal through its immunoreceptor tyrosine-based activation motifs (ITAMs)-containing cytoplasmic tail [4]. Phosphorylation of these ITAMs by protein tyrosine kinases will then allow other molecules to interact with the TCR complex [5]. Engagement of the TCR, aided by co-stimulatory molecules such as CD28 at the immunological synapse, will then activate a wide range of intracellular pathways including Activator protein 1 (AP-1), Nuclear factor of activated T-cells (NFAT), Nuclear factorkappa B (NF- $\kappa \mathrm{B})$, and mammalian target of rapamycin (mTOR) [6]. While triggering of the TCR is a pre-requisite for T-cell activation and differentiation, a sustained stimulation can lead to the loss of T-cell functions. In several settings, this is part of homeostatic processes that not only contribute to limit systemic inflammation, but also protect the $\mathrm{T}$ cells themselves against their own demise. Thus, the dysfunctional T-cell status will result from the sum of physiological countermeasures aimed at controlling T-cell responses and preventing hyper-activation. T-cell dysfunction is defined by different transcriptional, phenotypic, and functional features, which encompasses several cellular states such as terminal differentiation, exhaustion, senescence and/or apoptosis (Figure 1) [7,8].

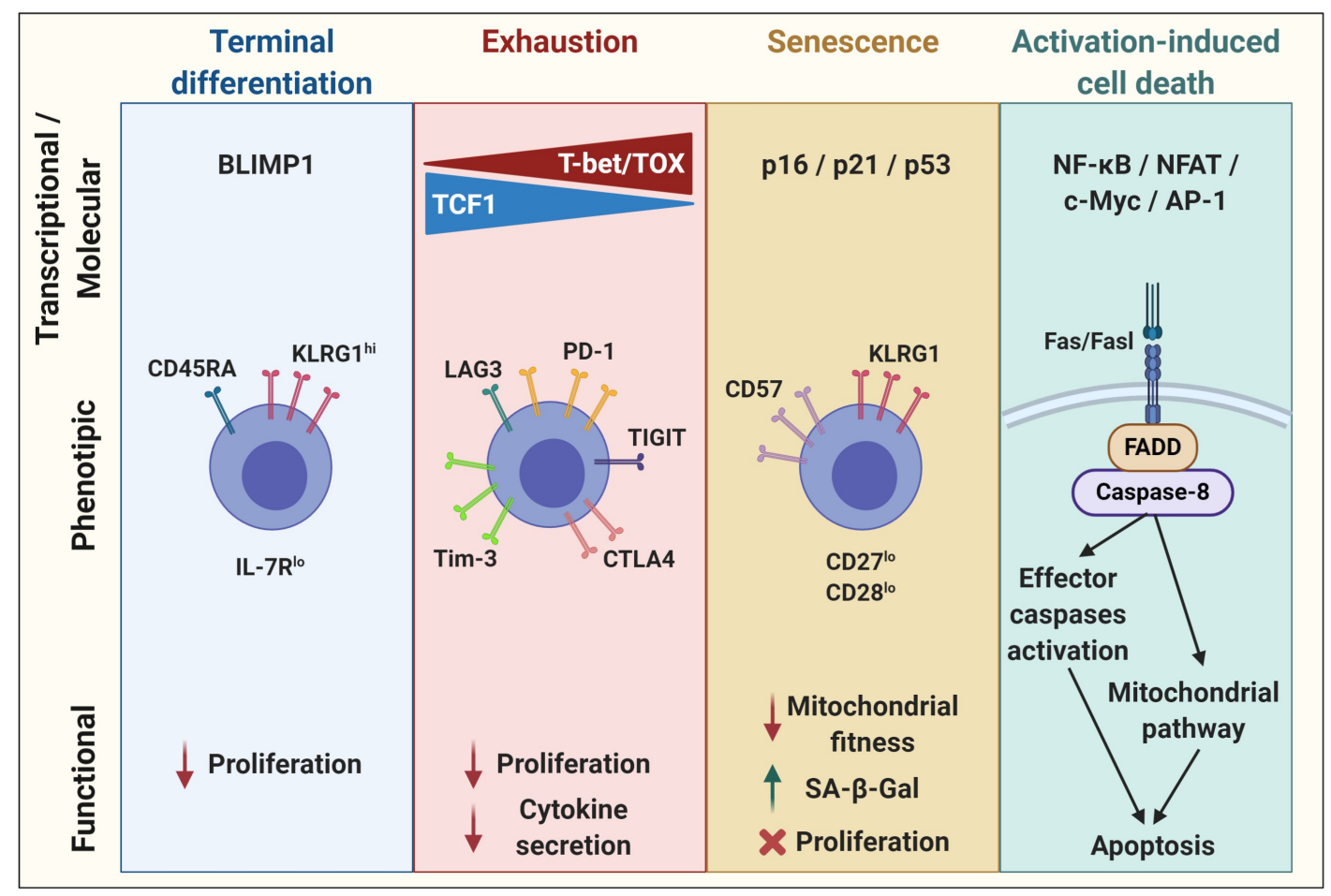

Figure 1. Characteristics of T-cell dysfunctional states. T-cell terminal differentiation, governed by the transcriptional repressor BLIMP1, is phenotypically associated with the re-expression of CD45RA, along with KLRG1, while downregulating IL-7R, leading to an impaired proliferation. T-cell exhaustion is regulated by a gradual decrease of TCF1, and concordant increase in T-bet and TOX expression, associated with the upregulation of many inhibitory receptors. In addition to a 
diminished proliferative capacity, exhausted $\mathrm{T}$ cells become hypo-responsive, mainly shown by an impaired cytokine secretion capacity upon stimulation. Senescent cells may engage various cell cycle regulators such as p16 or p21 via p53 expression. These cells will show upregulation of CD57 and/or KLRG1, and downregulation of co-stimulatory molecules CD27 and CD28. It is associated with impaired mitochondrial functions, increase in senescence-associated $\beta$-galactosidase (SA- $\beta-$ Gal) activity and proliferation arrest. Activation-induced cell death requires the activation of a death receptor, such as Fas, which will activate caspase-8 leading to direct effector caspases activation and/or mitochondrial release of cytochrome c, resulting in apoptosis.

\section{T-cell dysfunction; multifaceted extension of T-cell physiology}

The current use of $\mathrm{T}$ cells as therapy benefits from a large body of knowledge in Tcell dysfunction, obtained from both animal models and humans. This section summarizes the different mechanisms and cell states that can be regrouped under the general term of T-cell dysfunction. The extent to which these cellular states overlap or are exclusive still remains a matter of debate.

\subsection{Terminal differentiation}

In physiological conditions, while only a small number of cytotoxic T lymphocytes (CTL) will acquire memory properties following an immune response, a vast majority of effector cells will enter a state of terminal differentiation. Mainly described in well-characterized mouse model systems of infection, such as with lymphocytic choriomeningitis virus (LCMV), short-lived terminally differentiated CTL have been phenotypically associated with high expression of the NK cell maker killer cell lectin-like receptor G1 (KLRG1) and low expression of interleukin (IL)-7R $\alpha$ occurring with the graded expression of the transcription factor T-bet $[9,10]$. On the one hand, KLRG1 expression will impact proliferative capacity through the decrease of AKT, cyclin D and cyclin E activity as well as through an increase of cyclin inhibitor p27 expression [11]. On the other hand, the lack of IL-7R $\alpha$ will prevent T-cell proliferation in response to homeostatic cytokines [12-15]. In addition, these terminally differentiated $\mathrm{T}$ cells will re-express CD45RA and lose their migration properties in addition to proliferative capacity [10,16-18]. The transcriptional repressor B lymphocyte-induced maturation protein-1 (BLIMP1) may be the most determining factor orchestrating terminal effector differentiation of antigen-specific CD8 ${ }^{+} \mathrm{T}$ cells [19].

\subsection{Exhaustion}

T-cell exhaustion, driven by chronic TCR signaling, is another evolutionarily conserved process to sustained antigen stimulation aimed at reducing the risks of immunopathology or autoreactivity [20]. Exhausted T cells will express multiple inhibitory receptors such as PD1, TIM3, LAG3, CTLA4 and TIGIT, which will also lead to a loss of proliferative capacity and effector functions. This state is associated with a gradual increase in the expression of T-bet and a concomitant decrease in TCF1 expression, ultimately rendering exhaustion irreversible [21]. Lately, the role of the calcineurin-dependent transcription factor NFAT and other NFAT-driven transcription factors, such as Interferon regulatory factor 4 (IRF4), Basic Leucine Zipper ATF-Like Transcription Factor (BATF), nuclear receptor subfamily 4 group A (NR4A), and Thymocyte selection-associated high mobility group box protein (TOX), have been associated with the expression of these checkpoint receptors as well as the maintenance and survival of exhausted T cells [22-26]. Moreover, TOX expression can further shape the exhaustion transcriptional program and epigenetic landscape of T cells [27]. As a result, these cells will have a reduced effector function, mainly shown by a hypo-responsiveness to stimulation and a decrease in cytokine secretion. 


\subsection{Senescence}

While more generally associated with aging, T-cell senescence is typically characterized by cell cycle arrest, activation of the DNA damage response, increased $\beta$-galactosidase activity, and dysfunctional mitochondria. These cells nonetheless remain viable and metabolically active [28-30]. T-cell senescence is mainly linked with a decrease in the expression of co-stimulatory molecules, such as CD28 and CD27, and an increase in KLRG1 and/or CD57 expression [31,32]. As the T cells divide due to repeated stimulation, they may enter a stage of replicative senescence and lose their proliferation capacity as a result of telomere erosion and a loss of telomerase activity [33-35]. Alternatively, a state of "premature" senescence may develop in T cells that sustain DNA damage. In both instances, the expression of cell cycle regulators will be upregulated. While p16 is mainly associated with cell stress and/or DNA damage, thus implicated in premature senescence, telomere attrition will induce p53 that will directly induce the negative cell cycle regulator p21. Both pathways will inhibit cyclin dependent kinase 4 (CDK4) and CDK6 to maintain the retinoblastoma $(\mathrm{RB})$ protein hypo-phosphorylated, preventing cell cycle transition from G1 to $S$ phase, leading to senescence [36-40]. In addition, telomere-independent, DNA damage-associated cellular senescence has also been linked to p38 mitogen-activated protein kinase (p38MAPK) signaling in activated T cells [41,42].

\subsection{Activation-induced cell death}

The maintenance of peripheral immune tolerance by activation-induced cell death (AICD) is another key physiological process in T-cell biology [43]. Indeed, TCR stimulation can result in the initiation of apoptosis. Although ligation of TNF- $\alpha /$ TNF receptor 1 and TRAIL/DR4/DR5 have been shown contribute to AICD [44,45], Fas/FasL is still the prototype receptor/ligand pair of the extrinsic pathway of apoptosis $[46,47]$. FasL expression on activated $\mathrm{T}$ cells is regulated by several transcription factors, including NF- $\kappa \mathrm{B}$, NFAT, early growth response (EGR) gene family transcription factors, c-Myc, AP-1, secretory protein-1 (SP-1), and IRFs [43]. Upon engagement, a death-inducing signaling complex will form with the adaptor protein Fas-associated death domain (FADD) and procaspase- 8 , leading to activation of caspase- 8 and subsequent activation of effector caspases resulting in apoptosis [48]. Activated caspase- 8 can further activate a mitochondria-mediated pathway by specific cleavage of the BH3-only B-cell lymphoma-2 (Bcl-2) family member Bid [49,50]. This will converge towards the intrinsic apoptosis pathway involving other pro-apoptotic Bcl-2 family members, such as Bim, in mitochondria [51,52]. Conversely, T-cell survival mediated by the anti-apoptotic Bcl-2 protein was shown to be largely dependent on IL-7 homeostatic effect [53,54]. As for the other dysfunctional cell states, the nature as well as signal strength of the T-cell stimulation will greatly influence cell fate $[55,56]$.

\section{Biology meets therapy; T-cell dysfunction in adoptive cell therapy}

This section will review the current ACT approaches and how the notions of T-cell dysfunction integrate in both the manufacturing phase and the post-infusion period. Approaches aimed at mitigating or reversing T-cell dysfunction will also be discussed.

\subsection{Conventional $T$ cells}

Adoptive transfer of ex vivo expanded T cells from the natural repertoire is a promising approach to treat a variety of cancers. However, this requires stimulatory signals to promote in vitro proliferation of $\mathrm{T}$ cells that will impart a T-cell differentiation program that is susceptible to induce T-cell dysfunction. Hence, understanding how T-cell dysfunction develops or is programmed by the ex vivo expansion process is imperative. Strategies to promote optimal differentiation and functionality are susceptible to promote better function and persistence of the transferred cells (Figure 2). 


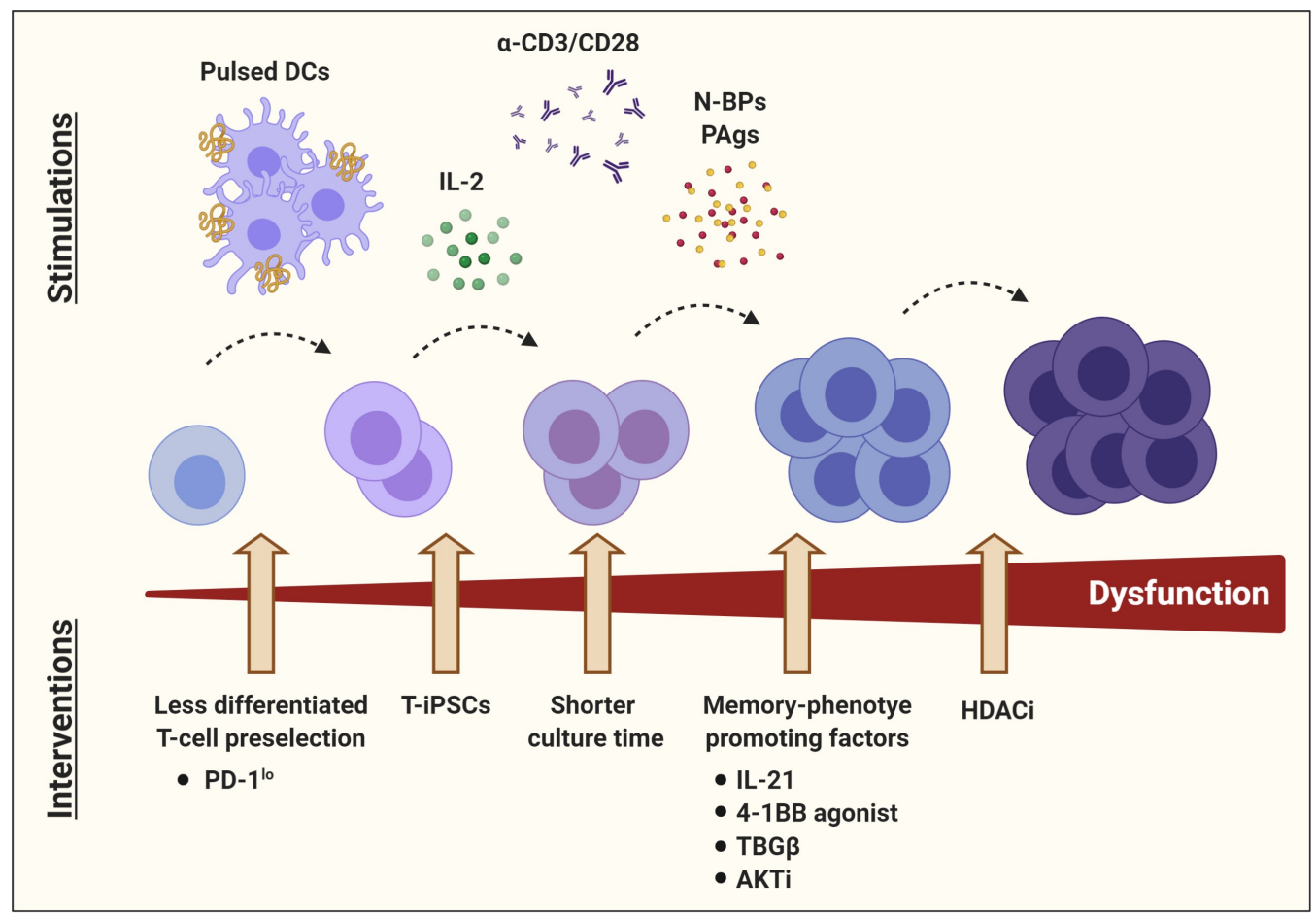

Figure 2. Interventions aiming at limiting T-cell dysfunction in unmodified cells for adoptive immunotherapy. Multiple stimulation methods are required depending on the T-cell subtype and antigen of interest. This can include the use of antigen-pulsed dendritic cells, anti-CD3 with or without anti-CD28, media supplementation with IL-2 or the use of aminobisphosphonates and phosphoantigens. Repetitive or chronic antigen stimulation will promote the gradual accumulation of dysfunctional cells over time. Many interventions are under investigation to maintain the cells in a less differentiated state. This can be done with pre-selection of $\mathrm{T}$ cells with a favorable phenotype, excluding cells expressing inhibitory receptors such as PD-1 (although these can sometimes represent precious antigen-specific $\mathrm{T}$ cells harvested from patients). Rejuvenation of dysfunctional $\mathrm{T}$ cells by induced pluripotent stem cell technology can also generate less differentiated cells. A shorter culture time allow to maintain a higher percentage of healthy cells but this may limit the number of cells manufactured. Addition of various factors to promote a memory phenotype differentiation is also evaluated. This encompasses the use of immunoregulatory cytokines (e.g. IL-21, TGF $\beta$ ), agonists of co-stimulatory molecules (e.g. 4-1BB), and inhibition of signaling pathways (e.g. AKTi). The targeting of histone deacetylase (HDACi) has further demonstrated its ability to limit T-cell differentiation.

Allogenic hematopoietic cell transplantation has not only been the first established form of ACT, it has also served as an ideal setting to advance the field. One of the greatest success of ACT in the wake of allogeneic hematopoietic cell transplantation has been the treatment of immunosuppression-associated opportunistic virus reactivations. Antiviral T cells expanded ex vivo have proved to be highly effective to control such viral reactivations in both hematopoietic and organ transplantation [57-61]. Over the years, manufacture time for these virus-specific T-cell products have gone from three months to around 10 days [62]. It is also possible to directly enrich virus-specific $T$ cells from a healthy donor apheresis product and administer the T cells without further expansion [63]. Most of the published experience with virus-specific $T$ cells reports on the generation of cellular products manufactured from a robust memory repertoire in healthy donors. Such memory cells readily expand in culture and show limited evidence of T-cell dysfunction at time of infusion. In hematopoietic cell transplantation, long term persistence of the transferred cells, establishing long-lasting memory in the recipients, has been shown when the virusspecific $\mathrm{T}$ cells are prepared from the original stem cell donor [58]. Yet, the stimulation and expansion of $\mathrm{T}$ cells from naïve repertoire has proven more difficult. Although clearly feasible for virus-specific $\mathrm{T}$ cells $[64,65]$, the generation and expansion of $\mathrm{T}$ cells targeting 
tumor-associated antigens (TAA) or transplantation antigens from naïve repertoires require more elaborate culture processes [1,2,66-68].

Alloreactive donor T cells can recognize Major histocompatibility complex (MHC)bound polymorphic peptides derived from the host proteome known as minor histocompatibility antigens (MiHAs) [69-72]. Most of the molecularly characterized MiHAs are encoded by autosomal genes that differ between patient and donor secondary to germline encoded non-synonymous single nucleotide polymorphisms (ns-SNP). Although potent immunogenic antigens, up to 5 rounds of ex vivo weekly stimulation with antigen loaded dendritic cells and the presence of interleukin (IL)-2 are often needed to generate high numbers of specific CD8 ${ }^{+} \mathrm{T}$ cells [2]. However, despite the immunogenic nature of these antigens, protocols often generate dysfunctional cells which highly impede cell functionality and persistence after adoptive transfer $[67,68]$. Ex vivo repeated antigen exposure in the context of stimulatory cytokines blunts T-cell growth and leads to terminal differentiation and exhaustion markers expression especially on antigen-specific T cells in the culture [2].

It is now generally accepted that optimal therapeutic effects are achieved when the ex vivo generated $\mathrm{T}$ cells maintain features associated with early memory differentiation (memory stem cell - Tscm, or central memory - Tcm) [73,74]. Clinical outcome might thus depend more on the antigen-specific T-cell early differentiation phenotype, leading to a better ability to proliferate and persist in vivo, rather than on the bulk number of infused cell [75]. As such, careful design of ex vivo culture conditions may promote the acquisition of a favorable differentiation status. Exogenous cytokines, small molecules and metabolic modulation during ex vivo priming and expansion phase may confer early memory features. [76]. We and others have demonstrated that exogenous exposure to IL-21 can limit terminal differentiation of antigen-specific $T$ cells which can increase their in vivo persistence and promote phenotypic and functional characteristics associated with long-lived memory T cells [66,77]. Histone deacetylase inhibitor (HDACi) combined with IL-21 can also reprogram differentiated $\mathrm{CD}^{+} \mathrm{T}$ cells into central memory-like $\mathrm{T}$ cells. This is achieved through the increase in histone $\mathrm{H} 3$ acetylation and chromatin accessibility at the CD28 promoter region. It is then followed by a IL-21-mediated phosphorylation of Signal transducer and activator of transcription 3 (STAT3) binding to the CD28 region, and a resulting memory-associated transcriptional signature [78]. A brief exposure to transforming factor beta (TGF $\beta$ ) similarly promotes Tcm differentiation by mitigating Tcell activation signals [76]. Along the same lines, AKT inhibition has also been shown to increase early T-cell memory features [79].

Nonetheless, relying solely of phenotyping may be misleading. The proportion of effector memory or central memory phenotype cells do not necessarily correlate with $e x$ vivo loss of antigen-specific cells or decline in their functionality [2]. While repeated antigenic stimulation of MiHA-specific T cells may lead to terminal differentiation, prolonging the expansion phase in the absence of antigenic stimulation can decrease T-cell proliferation despite limited expression of inhibitory receptors and the preservation of polyfunctional cytokine secretion by the remaining antigen-reactive cells. Thus, the analysis of both phenotypic and functional properties of T cells prior to ACT may best inform about the potency of the T-cell product [75]. In addition, it has been shown that a fraction of terminally differentiated melanoma-specific or leukemia-specific CTL clones after ex vivo expansion appear to revert back to a central memory type in vivo after ACT, potentially conferring clinical benefits [66,80].

As an alternative to limiting the development of dysfunction, some groups have concentrated on cell reprogramming. A terminally differentiated or exhausted T cell may be induced into a pluripotent stem cell (iPSCs), which enables re-differentiation into a naïve or central-memory phenotype T cell with the re-expression of CCR7, CD27, and CD28 and no exhaustion markers [81-84]. An interesting characteristic of iPCS generated from lymphocytes is their ability to keep the rearranged TCR loci of the parental cells, which will remain unchanged during in vitro differentiation $[81,83]$. As such, antigen-specific CTL 
clones can be pre-selected and reprogrammed into iPSC (T-iPSCs) with the Yamanaka transcription factors (Oct3/4, SOX2, KLF4, and c-MYC) [81-83,85,86]. These new CTLs will then have longer telomeres than the original cells, with higher proliferative and functional capacities [81]. Furthermore, exhausted T cells turned into T-iPSCs will be functionally able to respond to antigen-specific stimulation [87]. However, a caveat with the use of iPSC in cell therapy is the risk of only partial re-differentiation and teratoma formation post-transfer.

\subsection{Unconventional T cells}

$\gamma \delta$ TCR-expressing T lymphocytes is another T-cell subtype with effector and regulatory functions and the ability to infiltrate tumors. Adoptive cell therapy with human $\gamma \delta$ T cells expressing a V $\gamma 2 \mathrm{~V} \delta 2$ TCR has shown promise because of their capacity to recognize and kill most types of tumors in a MHC-unrestricted manner [88]. V $\gamma 9 \mathrm{~V} \delta 2 \mathrm{~T}$ cells are relatively abundant in human blood and can be easily ex vivo expanded in response to amino-bisphosphonates (N-BPs) or phosphoantigens (PAgs). However, culture conditions, timing and dosage of N-BPs or PAgs, as well as added co-stimulators like IL-2, may result in different phenotypes and effector cell characteristics $[89,90]$. Results of in vitro expansion are often highly donor dependent and may also predict the respective in vivo expansion efficacy, which can be additionally restricted in cancer patients. Currently, optimal doses of N-BPs or PAgs as well IL-2 has not yet been determined for ex vivo expansion. The efficacy of stimulation may depend on drug concentration as well as duration of exposure and have to be individualized [91]. The role for additional systemic application of N-BPs in context of adoptive cell transfer strategies also remains elusive. On the one side, it has been reported to promote engraftment of ex vivo-stimulated and adoptively transferred human cells in mice, but on the other side, there are indications that repetitive application of these drugs in vivo induces V $\gamma 9 \mathrm{~V} \delta 2 \mathrm{~T}$-cell exhaustion [89]. As an alternative, some groups tried to adoptively transfer PD-1 ${ }^{\text {lo }} \mathrm{V} \delta 2^{+} \mathrm{T}$ cells to bypass the tumor immunosupressive environment in vivo [92].

Other T cells with "innate-like" characteristics can recognize vitamin metabolites, small phosphoantigens, and lipid antigens presented within various highly conserved and non-polymorphic MHC class I-like molecules [93-96]. One of the best characterized subset is invariant Natural Killer T (iNKT) cells, which recognize lipid antigens bound within the antigen-presenting molecule CD1d [97]. These cells utilize the near-germline TCR $\alpha$ rearrangement $\mathrm{V} \alpha 24-\mathrm{J} \alpha 18$ combined with a limited TCR $\beta$ repertoire and are functionally defined by their ability to respond to galactosylceramide ( $\alpha$-GalCer) when presented by CD1d molecules [93-96,98,99]. They are potent cytokine secretors that bridge innate and adaptive immunity [95,97]. These cells have thus been investigated as cell transfer therapy product [100-105]. However, whether these cells develop dysfunctional features prior, during, and after therapy is still unclear. Nevertheless, since iNKT cells have been shown to limit Graft-versus-host disease (GvHD) [106], there is a growing interest to use them as a platform for cell engineering [107].

The development of ACT using other lymphoid cells is also rapidly expanding. Innate lymphoid cells (ILCs) derive from common lymphoid progenitors in the bone marrow that lack other lineage markers and genetically rearranged antigen receptors. They are defined according to their cytokine production pattern as well as unique transcription factors [108-110]. Group 1 ILCs (ILC1s) secrete IFN $\gamma$ and express the transcription factor T-bet whereas ILC2s produce IL-5 and IL-13 and require expression of Gata3 [111114]. ILC3s will generate IL-22 and IL-17 and are defined by the expression of ROR $\gamma \mathrm{t}$, same as lymphoid tissue-inducer cells which also express IL-7R $\alpha$ [115-117]. Since ILCs can respond to many danger signals like innate immune cells, and secrete cytokines like $\mathrm{T}$ cells despite the lack of TCR, different therapeutic approaches aim at targeting these cells in vivo to improve the efficacy of tumor immunotherapies [118]. While the mechanisms 
underlying dysfunction in these cell subtypes may not be as well understood as for conventional T cells, several strategies emerge to enhance both the in vitro expansion of these cells and their therapeutic potential.

\subsection{NK cells}

Natural killer (NK) cells can produce a vast array of cytokines/chemokines and are key players in immune responses regardless of the recipient's HLA haplotype. NK cells can also directly regulate $\mathrm{T}$-cell responses as well as modulate antigen-presenting cell activation. In solid tumors, NK cells secretion of CC-chemokine ligand 5 (CCL5), XC-chemokine ligand 1 (XCL1) and XCL2, and IFN $\gamma$ can promote the recruitment of dendritic cells and further mediate their activation, which have been shown to improve patient outcome $[119,120]$. However, as with T cells, NK cells can become exhausted and blockade of TIGIT has demonstrated potential at preventing NK-cell dysfunction. Hence, direct checkpoint blockade in NK cells may result more potent tumor-specific T-cell response in an NK celldependent manner [121,122].

Activated NK cells also upregulate many receptors, which can be shaped according to culture conditions and media supplementation with cytokines such as IL-2, IL-12, IL15, IL-18, or IL-21 and Type I IFNs [123-130]. Hence, ex vivo modulation of NK-cell receptor expression have also been extensively investigated to overcome dysfunction. In general, PBMCs are first depleted for CD3+ cells and enriched for CD56+ cells, then cultured in medium containing IL-2 for up to 2 weeks $[126,131]$. This ex vivo stimulation induces NK-cell cytokine secretion, STAT3/AKT signaling, and upregulation of NKG2D receptor [132]. IL-2 can also enhance NK-cell response to IL-12 by increasing the expression of its receptor [133]. IL-15 supplementation have later been used to inhibit activation-induced cell death, activate mTOR pathway and stress-activated genes, which confers better antitumor capacity [134-136]. However, continuous IL-15 signaling have been linked to functional NK-cell exhaustion by decreased fatty acid oxidation [137]. Moreover, it was shown that IL-12-mediated IFN $\gamma$ production of NK cells requires priming with IL-18, a cytokine also known to enhance IL-15-induced NK-cell proliferation [138,139]. Finally, IL-21 have been used to further increase NK-cell proliferation and effector functions, even though it can trigger apoptosis in vitro [140-143]. Other studies demonstrated that the time span NK cells are exposed to IL-21 is in fact critical [144,145]. Moreover, since NK cells can also express the inhibitory receptor PD-1, it has been found that blockade of the PD-1/PD-L1 axis can improve NK cell-mediated immunity to tumors and this response in indispensable for the full therapeutic effect of immunotherapy [146].

Another issue to consider is the NK-cell expansion and functional status from heavily pretreated, thus immunocompromised patients, which are much poorer than for allogeneic NK cells [147]. Other than cytokine supplementation, investigation on feeder cells required for in vitro culture are underway. In a phase I clinical trial (clinicaltrials.gov \#NCT02481934), autologous NK cells were activated by an engineered K562 cell-expressed membrane-bound form of IL-15 and 4-1BB ligand. NK cells can also be differentiated from CD34+ umbilical cord blood progenitors as an allogenic cell source (clinicaltrials.gov \#NCT01729091).

\subsection{Tumor-infiltrating lymphocytes}

Tumor-infiltrating lymphocytes (TIL) are composed of antigen-experienced and "passenger" $\mathrm{T}$ cells found at the tumor site. The tumor reactive $\mathrm{T}$ cells are subjected to repeated antigen encounters. When harvested for immunotherapy purposes, these cells already exhibit signs of dysfunction that may in fact identify the cancer-reactive $\mathrm{T}$ cells [148]. Still, they can be expanded prior to re-infusion into the patient. While standard protocols use anti-CD3 stimulation with IL-2, generating T cells with a more advanced differ- 
entiation state, some groups focused on cytokine combination cocktail during the expansion phase to increase cell functionality or on the selection of less differentiated TILs among the tumor $[17,149-151]$.

TILs found in solid tumors indeed represent a heterogeneous population. It was recently discovered that TILs can be divided into two functionally distinct subsets [152]. The first is the most abundant and is constituted of a clonally related terminally differentiated population that express high levels of inhibitory receptors. The other is a TCF1+ stem-like CD8+ T-cell population, which is suggested to be a major factor in the success or failure to eradicate a tumor depending on their ability to be sufficiently stimulated by an antigenpresenting-cell niche and to continuously produce terminally differentiated CD8+ T cells within the tumor [152].

It has also been found that the presence of the integrin $\alpha \mathrm{E} \beta 7$ (CD103), characteristic of tissue-resident memory T cells (Trm), is positively associated with cytokine production, whereas expression of the transcription factor Eomes is negatively associated with TIL function, suggesting a competition between an antitumor CD103+ Trm-like and an exhaustion program [153]. CD69+CD103+ Trm cells usually reside in non-lymphoid tissues and function as a first line of defense against secondary infections. In addition to their unique anatomic location, Trm have distinct transcriptional profiles showing the upregulation of inhibitory receptors such as PD-1. However, human Trm have an enhanced capacity for production of certain cytokines and regulatory molecules and a decreased turnover compared to circulating effector memory $\mathrm{T}$ cells, suggesting long term maintenance in situ [154]. Furthermore, it has been demonstrated that the transcription factor Bhlhe40 is specifically required for both Trm and TIL development as well as their polyfunctionality by sustaining mitochondrial fitness and a functional epigenetic state. Local PD-1 signaling in the tumor microenvironment inhibits TIL Bhlhe40 expression, and Bhlhe40 is critical for TIL reinvigoration following anti-PD-L1 blockade [155].

Another approach to improve TILs fitness is to target the member of the tumor necrosis factor receptor superfamily T-cell co-stimulatory receptor 4-1BB (CD137). As 4-1BB is frequently present on non-exhausted CD8+ TILs, 4-1BB agonist and PD-1 blockade demonstrated a synergistic survival benefit in a CD8+ T-cell dependent manner. As such, combined treatment decreased TIL exhaustion and improved TIL functionality in a glioblastoma model [156]. Similarly, PD-1 blockade and 4-1BB stimulation were demonstrated as an effective strategy to improve pancreatic tumor-reactive TILs yield [157].

Following tumor infiltration, T cells interact with other immune, cancer and stromal cells within the tumor microenvironment (TME). Cells comprised in this environment may develop premature senescence caused by external factors such as TME metabolic changes or drug and radiation therapy [158]. Senescent cells will stay metabolically active but will cease to proliferate $[159,160]$. Another important characteristic of senescent cells is that the expression of many genes changes during senescence and gives rise to what is called the senescence-associated secretory phenotype (SASP) [161]. Senescent cells secrete numerous biologically active factors, including cytokines, chemokines, growth factors and proteases $[162,163]$. Because these secreted factors act in autocrine and paracrine manners and have pleiotropic effects on surrounding cells, they may virtually affect any cell type within the tumor microenvironment, including infiltrating $\mathrm{T}$ cells. Indeed, tumorinduced senescence in T cells can be reproduced in vitro by briefly incubating cells in conditions of low tumor to $\mathrm{T}$ cell ratio. Furthermore, senescent $\mathrm{T}$ lymphocytes become able to suppress proliferation of normal T cells and promote tumor immune evasion [164]. In antiCD3 + IL-2 stimulated T cells, inhibition of p38MAPK signaling proved to be helpful to reverse the senescence phenotype of CD8+ T cells by increasing their proliferation and functionality $[41,42]$. 


\subsection{T-cell receptor (TCR) transgenic cells}

Genetic engineering offers several possibilities such as conferring new antigenic specificities to T cells and circumvent certain limitations linked to T-cell dysfunction. These approaches provide many advantages as they minimise culture duration and offer the possibility to directly modulate key signaling pathways within engineered cells to reduce dysfunction (Figure 3). Among these strategies is the introduction of an artificial TCR into antigen-specific conventional T cells. Activation through the endogenous TCR can increase the expression of the introduced TCR and subsequently activate the TCR-T cells. Although it can restore more potent antitumor activity [165], TCR gene transfer is fraught with the risk of inappropriate pairing between exogenous and endogenous TCR chains. A mixed dimer formation can result in suboptimal activity and novel off-target antigen reactivity, potentially leading to harmful immune side effects. Moreover, the transduced TCR must successfully compete with the endogenous TCR chains to form a ternary complex with the CD3 signaling complex [166]. Hence, native TCR $\beta$ gene, or simultaneous $\mathrm{TCR} \alpha / \beta$ genes, have been knocked out using clustered regularly interspaced short palindromic repeats (CRISPR)/Cas9 technology prior to transduction with a cancer-specific receptor of choice, resulting in a stronger, and more polyfunctional response of engineered T cells when tested against target cancer cell lines $[167,168]$. Remarkably, the combination of CRISPR/Cas9 and TCR transgenic therapy has recently been used to knock out both the endogenous TCR chains and the negative co-signaling receptor PD-1 to redirected T cells bearing a transgenic TCR targeting a TAA from NY-ESO-1 [169].

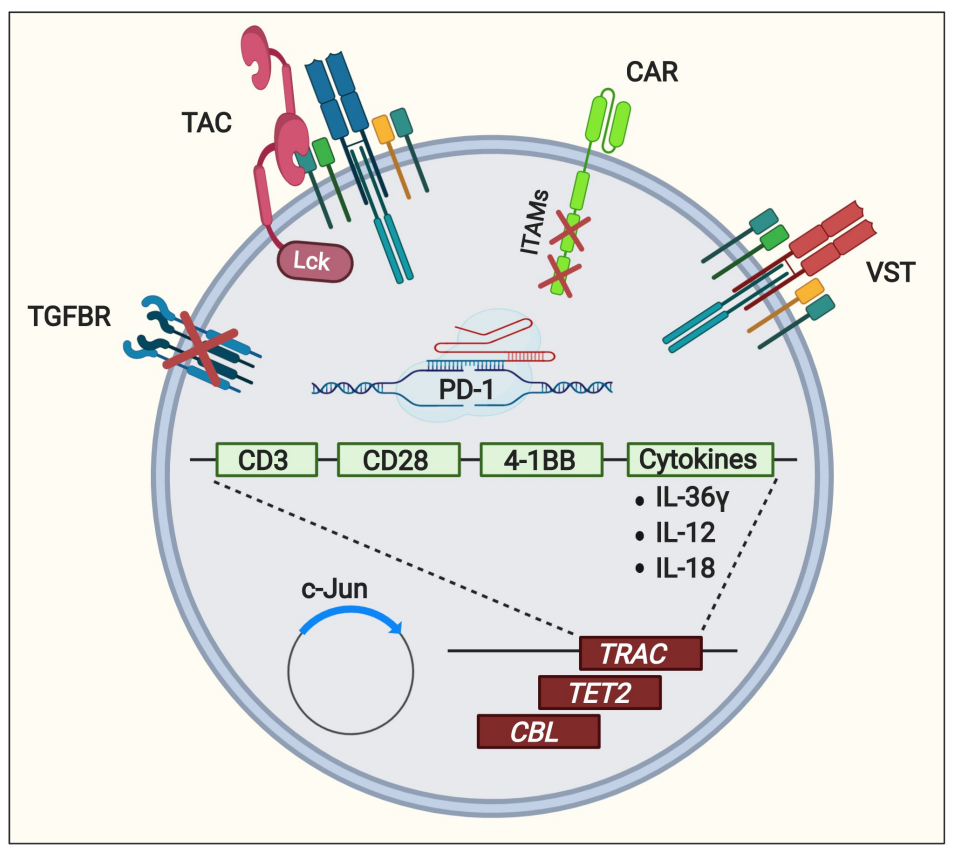

Figure 3. Interventions aiming at limiting T-cell dysfunction in engineered cells for adoptive immunotherapy. Engineered cells comprise transgenic TCR and chimeric/synthetic antigen receptor T cells. Virus-specific T cells (VST) has been evaluated as a platform for artificial receptor expression in order to leverage their robust memory differentiation, but disruption of the endogenous $\mathrm{TCR} \alpha / \beta$ chains by CRISPR/Cas9 or specific integration of the CAR vector into targeted DNA locus (e.g. TRAC) have shown additional efficacy. This was also true when CAR constructs inadvertently disrupted the TET2 and CBL genes. Other strategies to increase modified T-cell fitness are the blockade of suppressive cytokine signaling, here shown by the overexpression of a dominant negative TGF $\beta$ receptor, or the use of a T-cell antigen coupler (TAC) to avoid tonic signaling and leverage endogenous TCR signaling. Advanced engineering of CAR molecules involving the inactivation of two out of three ITAM motifs and increase in c-Jun activity can further limit tonic sig- 
naling and T-cell dysfunction. Alternatively, the genetic ablation of negative co-signaling molecules (e.g. PD-1) may be used to circumvent the effects of T-cell dysfunction. Other strategies also include the enhancement of T-cell function through the production of stimulatory cytokines (e.g. IL-36y, IL-12 and IL-18) or co-stimulatory molecules (e.g. CD28 and 4-1BB). .

Introduction of a transgenic TCR into virus-specific T cells (VSTs) to redirect their specificity towards cancer antigens have also been investigated [170-174]. However, expression of a transgenic TCR often results in the downregulation of the endogenous TCR which unfortunately leads to a reduced anti-viral reactivity [170-175]. This is in part explained by the competition for TCR signaling components by the endogenous and exogenous TCRs, and as possible consequences, one may expect lessened control of viral reactivations post-transplantation and poor capacity of TCR-transgenic VSTs to re-expand in vivo upon viral reactivation or vaccination $[174,175]$. The addition of CD $8 \alpha \beta$ into the transgenic TCR vector has been used to rescue endogenous MHC class I-restricted anti-viral TCR function [176,177]. These TCR-transgenic VSTs have a predominant central-memory phenotype and their anti-viral reactivity is preserved together with their anti-tumor function [178]. The insertion of the CD8 $\alpha \beta$ co-receptor also improved antigen recognition by the TCR/MHC complex, recruitment of the tyrosine kinase Lck to the immune synapse, and proper activation of signaling components for T-cell activation, in addition to allowing CD4 ${ }^{+} \mathrm{T}$ cells to recognize MHC class I-restricted antigens $[179,180]$.

Another strategy to redirect T cells in a TCR-dependent, MHC-independent manner has been the use of a T-cell antigen coupler (TAC) composed of an antigen-binding domain, a TCR-recruitment domain, and a co-receptor domain [181]. This design recapitulates the architecture of a TCR complex and engages natural cellular pathways. In addition, these modified cells do not show signs of tonic signaling and display a less differentiated phenotype, which results in a potent T-cell product. These TAC-T cells also showed efficient tumor tissue infiltration at early time points post-ACT and great anti-tumor efficacy in a pre-clinical in vivo model of solid tumor [181]. Along the same lines, another group has fused TCR subunits to an antibody-based binding domain to reprogram T-cell specificity in an HLA-independent manner while still taking advantage of the endogenous TCR signaling. These cells showed tumor cell killing in vivo, although they were less efficient in cytokine production suggesting some degree of dysfunctionality [182].

\subsection{Chimeric antigen receptor (CAR) T cells}

Engineered $\mathrm{T}$ cells for the expression of an artificial receptor have seen the light in 1989 [183]. This first-generation chimeric antigen receptor (CAR) T cell, composed of a CD3 $\zeta$ chain, containing three ITAMs for TCR-like signal transduction, fused with single chain fragment of variable region ( $\mathrm{scFv}$ ) antibody, could support T-cell activation and cytotoxicity, but with very limited persistence and in vivo antitumor efficacy $[5,184,185]$. Second-generation CARs therefore incorporated the two-signal model of T-cell activation by modifying CAR vectors to include a CD28 or 4-1BB co-stimulatory domain providing signals for T-cell effector function, proliferation, and more importantly persistence [186,187]. Although complicated by massive activation and cytokine release syndrome, second-generation CD19-targeting CAR T cells have rapidly entered routine clinical care. Third-generation CAR T cells further incorporate more than one co-stimulatory domain and other modifications or include the inducible caspase-9 suicide gene system as a "safety switch" to limit on-target, off-tumor toxicities [188]. However, lack of CAR T-cell long term persistence, poor expansion after ACT and tumor immune escape remain cardinal limitations of this form of therapy [189]. Hence, several issues pertaining to intrinsic biologic T-cell

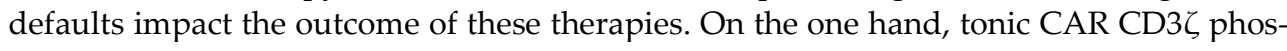
phorylation, triggered by antigen-independent clustering of $\mathrm{scFv}$, has been shown to induce early CAR T-cell exhaustion. Moreover, integration of CD28 co-stimulation into the CAR vector seems to increase, while 4-1BB co-stimulation limits exhaustion induced by

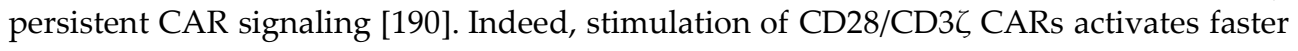


with larger-magnitude changes in protein phosphorylation, which correlates with an effector T-cell phenotype. In contrast, 4-1BB/CD3 $\zeta$ CAR T cells preferentially expresses Tcell memory-associated genes and exhibits sustained antitumor activity against established tumors in vivo [191]. Another way to address the issue of tonic signaling have been to calibrate the number of ITAMs on the CD3 moiety. While the presence of one, two, or three functional ITAMs do not impede in vitro function, a single ITAM-containing CAR can outperform the other forms in vivo. Remarkably, this modified vector also favors persistence of highly functional CAR T cells, inducing long-lived memory cells with effective anti-tumor properties [192].

Beyond concerns pertaining to T-cell engineering, the quality of the "input" material at the beginning of the manufacturing process impacts clinical outcomes. Autologous CAR T-cell efficacy greatly depends on the functional capacity of patients' endogenous $\mathrm{T}$ cells. Indeed, studies have shown that T-cell fitness diminishes throughout the progression of diseases such as chronic lymphocytic leukemia (CLL), implying impaired proliferative capacity, a dysfunctional phenotype, and a decreased T-cell cytotoxicity, which will impact the generation of CAR T cells [193-198]. Furthermore, molecular and functional Tcell defects are also acquired by co-culture of previously healthy T cells with CLL cells $[197,199,200]$. Among these defects, impairment of mitochondrial biogenesis and fitness, accompanied by reduced glucose transporter 1 (GLUT1) reserves, have been identified, which negatively correlates with the persistence of the transferred CAR T cells and clinical outcome [201]. It was further shown that the frequency of memory $\mathrm{T}$ cells, defined by a CD8+CD45RO-CD27+ population, in the pre-manufacturing leukapheresis product, was significantly associated with clinical response [202,203]. Similarly, cell features and magnitude of ex vivo expansion when harvested after a response to induction therapy to manufacture B-cell maturation antigen (BCMA)-specific CAR T cells would be expected to be more clinically effective compared to leukapheresis product from relapsed/refractory multiple myeloma [204]. Finally, despite the generation of a lesser number of cells, the beneficial effects of reduced culture duration manifests in improved in vitro proliferation and effector function, which directly correlates with improved engraftment and anti-tumor function in vivo, even at a 6-fold lower dose [205].

Studies on CAR metabolic pathway activation revealed that AP-1, a transcription factor composed of dimers of c-Jun and c-Fos, was highly solicited. Its activity is regulated by extracellular signals that can repress or activate its transcription. The formation of the AP-1 complex, downstream of the TCR signaling, induces IL-2 transcription among other factors [206,207]. CAR T-cell exhaustion has also been associated with a profound defect in the production of IL-2, along with increased chromatin accessibility of AP-1 transcription factor motifs and overexpression of the basic leucine zipper (bZIP) and IRF transcription factors $[26,208,209]$. Thus, overexpression of c-Jun rendered CAR T cells resistant to exhaustion, enhanced their expansion potential, increased their functional capacity, and diminished their terminal differentiation [210].

The blockade of immunosuppressive pathways have also been investigated to confer superior functionality in CAR T cells. As such, it was demonstrated that exposure to TGF $\beta$ impairs proliferation as well as cytokine production of Receptor Tyrosine Kinase Like Orphan Receptor 1 (ROR1)-specific CAR T cells co-cultured with ROR1-expressing triplenegative breast cancer cells. Thus, the blocking of TGF $\beta$ receptor signaling with a specific kinase inhibitor could promote better anti-tumor function in vitro [211]. However, this is to take with caution as TGF $\beta$ can also be beneficial for T-cell memory differentiation in certain contexts [212]. After adoptive transfer, the overexpression of a dominant negative TGF $\beta$ receptor or hybrid receptors converting an inhibitory signal (such as PD-1) into a stimulatory signal are additional strategies to enhance ACT efficacy [213,214]. Along the same lines, genetic ablation of negative co-signaling molecules such as PD-1 in CAR T cells, or CAR T cells secreting anti-PD-1 antibodies are currently investigated in clinical trials (clinicaltrials.gov \#NCT04213469, \#NCT04489862). 
Fourth-generation CARs, also called TRUCKs, are armored to improve cell fitness by the insertion of genes coding for other molecules, such as cytokines, in the CAR vector

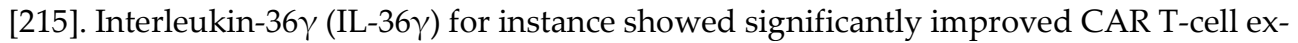
pansion and persistence, and resulted in superior tumor eradication compared to conventional CAR T cells. The enhanced cellular function by IL-36 $\gamma$ was mediated through an autocrine manner. Furthermore, activation of endogenous antigen-presenting and T cells by IL-36 $\gamma$ promoted a secondary anti-tumor response, which delayed the progression of antigen-negative tumor challenge [216]. IL-18-armored CAR T cells have also demonstrated enhanced proliferation and persistence in pre-clinical models, in addition to inducing a broadened anti-tumor response through endogenous immune effectors [217219]. Similarly, a CAR T cell secreting the pro-inflammatory cytokine IL-12 has demonstrated an improved cytotoxicity and the ability to overcome an immune inhibitory microenvironment in several models, but a clinical trial using IL-12-secreting TILs revealed the high risk of toxicity of this approach if IL-12 secretion is not limited in time and space $[220,221]$. An attractive strategy to limit cytokine secretion to activated T cells is to use a NFAT-inducible system [222].

As seen with conventional T cells, the use of endogenous TCR signaling has been investigated to improve expansion and function of CAR T cells. As such, virus-specific T cells have been modified with a CD19-specific CAR vector and infused into patients without prior cytoreductive chemotherapy. This approach is attractive for two reasons; it leverages the qualities of long-lived memory cells and can use viral reactivation as an adjuvant. In patients with viral reactivation, a striking proliferation of CAR T cells was observed with an associated depletion of CD19-expressing B cells suggesting that dual TCR and CAR stimulation can potentiate engineered cell expansion [223].

Since CAR constructs are usually generated with the use of viral vectors, integration may result in adverse effects such as oncogenic transformation or uncontrolled growth, transgene expression or transcriptional silencing [224]. In a case report of CD19-specific CAR T-cell infusion for CLL treatment, an impressive clinical response was associated with the persistence of one major T-cell clone. It was further shown that the random integration of the CAR vector had disrupted the methylcytosine dioxygenase TET2 gene, which led to an epigenetic profile consistent with altered T-cell differentiation and a central memory phenotype [225]. In a case of anti-CD22 CAR T-cell therapy to treat B-cell acute lymphoblastic leukemia (ALL), a dominant T-cell clone containing a copy of the vector integrated in the second intron of the E3 ubiquitin-protein ligase CBL gene was discovered. Loss of CBL has been associated with a reduction of the threshold for T-cell activation and dependence on co-stimulation [226]. As such, integration of the CAR vector in this region resulted in a dominant-negative effect with the normal CBL (and/or its homolog CBL-B) function, thus contributing to the hyper-expansion in response to a small amount of antigen [227]. Hence, attempts to direct the CAR vector into specific DNA regions are obviously of interest. Indeed, the targeted integration of a CD19-specific CAR vector into the T-cell receptor $\alpha$ constant (TRAC) locus have resulted in a more uniform CAR expression, while also limiting tonic CAR signaling and delaying effector T-cell differentiation and exhaustion [228].

Given that iPSCs can be easily amenable to genetic transformations in vitro, T-iPSCs can be genetically modified to augment their applicability, potency, and persistence and offers a great advantage compared to primary cells [229]. Thus, antigen specificity could be assigned to T-iPSCs by means of a chimeric receptor [230]. However, optimization is still needed as these first iPSC-derived CAR-expressing T cells were still prone to more a terminally differentiated phenotype [230].

\subsection{Other engineered cell types}

Other cell types have also gained interest for CAR engineering. For instance, CARmodified NK cells have shown a better safety profile than CAR T cells [231]. Furthermore, 
their shorter half-life, the smaller array of secreted cytokines limiting the possibility of cytokine release syndrome, their CAR-independent natural killing activity and their greater potential to be made as an "off-the-shelf" cellular product are among the most attractive features of CAR-NK cells [232-235]. Nonetheless, late differentiation and exhaustion remain an issue in CAR-NK ex vivo expansion protocols. As for CAR T cells, memory-like CAR-NK cells could be promoted when membrane-bound IL-21 was added with feeder cells [236]. Attempts have also been made to increase the lifespan of CAR-NK cells in vivo through an IL-15-armored CAR. A phase I/II study (clinicaltrials.gov \#NCT03056339) investigating NK cells engineered with a vector containing an anti-CD19 CAR, IL-15 and an inducible suicide gene, revealed a high response rate with an excellent toxicity profile [237]. Lastly, the use of cord blood NK cells as the primary cell source could generate greater numbers of CAR-NK cells, thus potentially reducing overall culture time per patient.

Recently, CAR-macrophages have also entered the field. As professional antigenpresenting cells, these modified cells can be reprogramed to direct their phagocytic activity against cancer cells. CAR-macrophages also show bystander effects by being able to activate dendritic cells and recruit CD8+ T cells to the tumor site [238].

\section{Conclusion}

Adoptive cell therapy is a promising approach that can be adapted to target virtually any cancer type or infection in a very dynamic manner. Indeed, as living drugs that can evolve with the patient, the ultimate goal is to cure and provide long term protection against relapse. To this end, finding suitable antigenic targets must be accompanied by strategies to generate cell products of higher quality in terms of activity and differentiation to increase persistence of the transferred cells, limit the development of dysfunction or circumvent its consequences. These interventions will depend on our evolving knowledge of the physiological processes governing immune cell differentiation. Important aspects, such as the plasticity and overlap between dysfunctional states, as well as how these cellular processes progress, remain elusive. The effects of manipulations aimed at these mechanisms may also induce compensatory pathways making these interventions unpredictable. Hence, research in the physiological mechanisms leading to cell dysfunction must be integrated with translational research in T-cell manufacturing as well as carefully designed clinical trials to reveal the most impactful biological processes to target in order to improve T-cell therapies.

Author Contributions: Both V.J and J.S.D performed the literature review, wrote, reviewed, and approved the final version of the manuscript.

Funding: This work was supported by Richard and Edith Strauss Foundation and Leukemia/Lymphoma Society of Canada (\#622735) operating grants held by J.S.D.

Acknowledgments: We are grateful to the Delisle laboratory members for helpful discussion and we apologize to authors we could not cite. J.S.D and V.J hold FRQS senior clinician researcher career award and post-doctoral fellowship, respectively. J.S.D is a Cole Foundation Early Career Transition Award laureate as well as a member of the ThéCell network and of the Canadian Donation and Transplant Research Program.

Conflicts of Interest: The authors declare no conflict of interest. The funders had no role in the design of the study; in the collection, analyses, or interpretation of data; in the writing of the manuscript, or in the decision to publish the results. 


\section{References}

1. Janelle, V.; Rulleau, C.; Del Testa, S.; Carli, C.; Delisle, J.-S. T-Cell Immunotherapies Targeting Histocompatibility and Tumor Antigens in Hematological Malignancies. Front. Immunol. 2020, 11, doi:10.3389/fimmu.2020.00276.

2. Janelle, V.; Carli, C.; Taillefer, J.; Orio, J.; Delisle, J.-S. Defining novel parameters for the optimal priming and expansion of minor histocompatibility antigen-specific T cells in culture. J. Transl. Med. 2015, 13, 123.

3. Gattinoni, L.; Klebanoff, C.A.; Restifo, N.P. Paths to stemness: building the ultimate antitumour T cell. Nat Rev Cancer 2012, 12, 671-684, doi:nrc3322 [pii]10.1038/nrc3322.

4. Samelson, L.E.; Patel, M.D.; Weissman, A.M.; Harford, J.B.; Klausner, R.D. Antigen activation of murine T cells induces tyrosine phosphorylation of a polypeptide associated with the $\mathrm{T}$ cell antigen receptor. Cell 1986, 46, 1083-1090, doi:10.1016/0092-8674(86)90708-7.

5. Bu, J.Y.; Shaw, A.S.; Chan, A.C. Analysis of the interaction of ZAP-70 and syk protein-tyrosine kinases with the T-cell antigen receptor by plasmon resonance. Proc. Natl. Acad. Sci. U. S. A. 1995, 92, 5106-5110, doi:10.1073/pnas.92.11.5106.

6. Hwang, J.-R.; Byeon, Y.; Kim, D.; Park, S.-G. Recent insights of T cell receptor-mediated signaling pathways for T cell activation and development. Exp. Mol. Med. 2020, 52, 750-761, doi:10.1038/s12276-020-0435-8.

7. Wherry, E.J. T cell exhaustion. Nat Immunol 2011, 12, 492-499.

8. Schietinger, A.; Greenberg, P.D. Tolerance and exhaustion: defining mechanisms of T cell dysfunction. Trends Immunol 2014, 35, 51-60, doi:10.1016/j.it.2013.10.001.

9. Jung, Y.W.; Rutishauser, R.L.; Joshi, N.S.; Haberman, A.M.; Kaech, S.M. Differential localization of effector and memory CD8 T cell subsets in lymphoid organs during acute viral infection. J. Immunol. 2010, 185, 53155325, doi:10.4049/jimmunol.1001948.

10. Kaech, S.M.; Cui, W. Transcriptional control of effector and memory CD8+ T cell differentiation. Nature reviews. Immunology 2012, 12, 749-761, doi:10.1038/nri3307.

11. Henson, S.M.; Franzese, O.; Macaulay, R.; Libri, V.; Azevedo, R.I.; Kiani-Alikhan, S.; Plunkett, F.J.; Masters, J.E.; Jackson, S.; Griffiths, S.J., et al. KLRG1 signaling induces defective Akt (ser473) phosphorylation and proliferative dysfunction of highly differentiated CD8+ T cells. Blood 2009, 113, 6619-6628, doi:10.1182/blood2009-01-199588.

12. Martin, M.D.; Badovinac, V.P. Defining Memory CD8 T Cell. Front. Immunol. 2018, 9, doi:10.3389/fimmu.2018.02692.

13. Kaech, S.M.; Tan, J.T.; Wherry, E.J.; Konieczny, B.T.; Surh, C.D.; Ahmed, R. Selective expression of the interleukin 7 receptor identifies effector CD8 T cells that give rise to long-lived memory cells. Nat. Immunol. 2003, 4, 1191-1198, doi:10.1038/ni1009.

14. Sarkar, S.; Kalia, V.; Haining, W.N.; Konieczny, B.T.; Subramaniam, S.; Ahmed, R. Functional and genomic profiling of effector CD8 T cell subsets with distinct memory fates. J. Exp. Med. 2008, 205, 625-640, doi:10.1084/jem.20071641.

15. Wilson, D.C.; Matthews, S.; Yap, G.S. IL-12 Signaling Drives CD8<sup $>+</$ sup $>$ T Cell IFN- $\gamma$ Production and Differentiation of KLRG1<sup $>+</$ sup $>$ Effector Subpopulations during $<$ em $>$ Toxoplasma gondii $</$ em $>$ Infection. The Journal of Immunology 2008, 180, 5935-5945, doi:10.4049/jimmunol.180.9.5935.

16. Fearon, D.T.; Manders, P.; Wagner, S.D. Arrested Differentiation, the Self-Renewing Memory Lymphocyte, and Vaccination. Science 2001, 293, 248, doi:10.1126/science.1062589. 
17. Klebanoff, C.A.; Gattinoni, L.; Restifo, N.P. CD8+ T-cell memory in tumor immunology and immunotherapy. Immunol. Rev. 2006, 211, 214-224, doi:https://doi.org/10.1111/j.0105-2896.2006.00391.x.

18. Lanzavecchia, A.; Sallusto, F. Progressive differentiation and selection of the fittest in the immune response. Nature Reviews Immunology 2002, 2, 982-987, doi:10.1038/nri959.

19. Rutishauser, R.L.; Martins, G.A.; Kalachikov, S.; Chandele, A.; Parish, I.A.; Meffre, E.; Jacob, J.; Calame, K.; Kaech, S.M. Transcriptional Repressor Blimp-1 Promotes CD8+ T Cell Terminal Differentiation and Represses the Acquisition of Central Memory T Cell Properties. Immunity 2009, 31, 296-308, doi:https://doi.org/10.1016/j.immuni.2009.05.014.

20. Blank, C.U.; Haining, W.N.; Held, W.; Hogan, P.G.; Kallies, A.; Lugli, E.; Lynn, R.C.; Philip, M.; Rao, A.; Restifo, N.P., et al. Defining ‘T cell exhaustion'. Nature Reviews Immunology 2019, 19, 665-674, doi:10.1038/s41577-019-0221-9.

21. Beltra, J.C.; Manne, S.; Abdel-Hakeem, M.S.; Kurachi, M.; Giles, J.R.; Chen, Z.; Casella, V.; Ngiow, S.F.; Khan, O.; Huang, Y.J., et al. Developmental Relationships of Four Exhausted CD8(+) T Cell Subsets Reveals Underlying Transcriptional and Epigenetic Landscape Control Mechanisms. Immunity 2020, 52, 825-841.e828, doi:10.1016/j.immuni.2020.04.014.

22. Martinez, G.J.; Pereira, R.M.; Äijö, T.; Kim, E.Y.; Marangoni, F.; Pipkin, M.E.; Togher, S.; Heissmeyer, V.; Zhang, Y.C.; Crotty, S., et al. The Transcription Factor NFAT Promotes Exhaustion of Activated CD8+ T Cells. Immunity 2015, 42, 265-278, doi:https://doi.org/10.1016/j.immuni.2015.01.006.

23. Khan, O.; Giles, J.R.; McDonald, S.; Manne, S.; Ngiow, S.F.; Patel, K.P.; Werner, M.T.; Huang, A.C.; Alexander, K.A.; Wu, J.E., et al. TOX transcriptionally and epigenetically programs CD8+ T cell exhaustion. Nature 2019, 571, 211-218, doi:10.1038/s41586-019-1325-x.

24. Seo, H.; Chen, J.; González-Avalos, E.; Samaniego-Castruita, D.; Das, A.; Wang, Y.H.; López-Moyado, I.F.; Georges, R.O.; Zhang, W.; Onodera, A., et al. TOX and TOX2 transcription factors cooperate with NR4A transcription factors to impose CD8(+) T cell exhaustion. Proc. Natl. Acad. Sci. U. S. A. 2019, 116, 12410-12415, doi:10.1073/pnas.1905675116.

25. Scott, A.C.; Dündar, F.; Zumbo, P.; Chandran, S.S.; Klebanoff, C.A.; Shakiba, M.; Trivedi, P.; Menocal, L.; Appleby, H.; Camara, S., et al. TOX is a critical regulator of tumour-specific T cell differentiation. Nature 2019, 571, 270-274, doi:10.1038/s41586-019-1324-y.

26. Man, K.; Gabriel, S.S.; Liao, Y.; Gloury, R.; Preston, S.; Henstridge, D.C.; Pellegrini, M.; Zehn, D.; BerberichSiebelt, F.; Febbraio, M.A., et al. Transcription Factor IRF4 Promotes CD8(+) T Cell Exhaustion and Limits the Development of Memory-like T Cells during Chronic Infection. Immunity 2017, 47, 1129-1141.e1125, doi:10.1016/j.immuni.2017.11.021.

27. McLane, L.M.; Abdel-Hakeem, M.S.; Wherry, E.J. CD8 T Cell Exhaustion During Chronic Viral Infection and Cancer. Annu. Rev. Immunol. 2015, 37, 457-495, doi:10.1146/annurev-immunol-041015-055318.

28. Jennifer, P.C.; Rita, B.E. T Cell Replicative Senescence in Human Aging. Curr. Pharm. Des. 2013, 19, 1680-1698, doi:http://dx.doi.org/10.2174/1381612811319090016.

29. Akbar, A.N.; Henson, S.M. Are senescence and exhaustion intertwined or unrelated processes that compromise immunity? Nat Rev Immunol 2011, 11, 289-295, doi:10.1038/nri2959.

30. Hernandez-Segura, A.; Nehme, J.; Demaria, M. Hallmarks of Cellular Senescence. Trends Cell Biol. 2018, 28, 436-453, doi:https://doi.org/10.1016/j.tcb.2018.02.001.

31. Henson, S.M.; Akbar, A.N. KLRG1--more than a marker for T cell senescence. Age (Dordrecht, Netherlands) 2009, 31, 285-291, doi:10.1007/s11357-009-9100-9. 
32. Xu, W.; Larbi, A. Markers of T Cell Senescence in Humans. International Journal of Molecular Sciences 2017, 18, 1742.

33. Effros, R.B.; Pawelec, G. Replicative senescence of T cells: does the Hayflick Limit lead to immune exhaustion? Immunol. Today 1997, 18, 450-454, doi:https://doi.org/10.1016/S0167-5699(97)01079-7.

34. Effros, R.B. Replicative senescence in the immune system: impact of the Hayflick limit on T-cell function in the elderly. Am. J. Hum. Genet. 1998, 62, 1003-1007, doi:10.1086/301845.

35. Hodes, R.J.; Hathcock, K.S.; Weng, N.P. Telomeres in T and B cells. Nat. Rev. Immunol. 2002, 2, 699-706, doi:10.1038/nri890.

36. Liu, Y.; Sanoff, H.K.; Cho, H.; Burd, C.E.; Torrice, C.; Ibrahim, J.G.; Thomas, N.E.; Sharpless, N.E. Expression of p16(INK4a) in peripheral blood T-cells is a biomarker of human aging. Aging Cell 2009, 8, 439-448, doi:10.1111/j.1474-9726.2009.00489.x.

37. Ben-Porath, I.; Weinberg, R.A. When cells get stressed: an integrative view of cellular senescence. The Journal of Clinical Investigation 2004, 113, 8-13, doi:10.1172/JCI20663.

38. Shawi, M.; Autexier, C. Telomerase, senescence and ageing. Mech. Ageing Dev. 2008, 129, 3-10, doi:10.1016/j.mad.2007.11.007.

39. Qian, Y.; Chen, X. Tumor suppression by p53: making cells senescent. Histol. Histopathol. 2010, 25, 515-526, doi:10.14670/hh-25.515.

40. Muñoz-Espín, D.; Serrano, M. Cellular senescence: from physiology to pathology. Nat. Rev. Mol. Cell Biol. 2014, 15, 482-496, doi:10.1038/nrm3823.

41. Henson, S.M.; Lanna, A.; Riddell, N.E.; Franzese, O.; Macaulay, R.; Griffiths, S.J.; Puleston, D.J.; Watson, A.S.; Simon, A.K.; Tooze, S.A., et al. p38 signaling inhibits mTORC1-independent autophagy in senescent human CD8+ T cells. The Journal of clinical investigation 2014, 124, 4004-4016, doi:10.1172/JCI75051.

42. Gurusamy, D.; Henning, A.N.; Yamamoto, T.N.; Yu, Z.; Zacharakis, N.; Krishna, S.; Kishton, R.J.; Vodnala, S.K.; Eidizadeh, A.; Jia, L., et al. Multi-phenotype CRISPR-Cas9 Screen Identifies p38 Kinase as a Target for Adoptive Immunotherapies. Cancer Cell 2020, 37, 818-833.e819, doi:10.1016/j.ccell.2020.05.004.

43. Arakaki, R.; Yamada, A.; Kudo, Y.; Hayashi, Y.; Ishimaru, N. Mechanism of activation-induced cell death of T cells and regulation of FasL expression. Crit. Rev. Immunol. 2014, 34, 301-314, doi:10.1615/critrevimmunol.2014009988.

44. Zheng, L.; Fisher, G.; Miller, R.E.; Peschon, J.; Lynch, D.H.; Lenardo, M.J. Induction of apoptosis in mature T cells by tumour necrosis factor. Nature 1995, 377, 348-351, doi:10.1038/377348a0.

45. Roberts, A.I.; Devadas, S.; Zhang, X.; Zhang, L.; Keegan, A.; Greeneltch, K.; Solomon, J.; Wei, L.; Das, J.; Sun, E., et al. The role of activation-induced cell death in the differentiation of T-helper-cell subsets. Immunol. Res. 2003, 28, 285-293, doi:10.1385/IR:28:3:285.

46. Itoh, N.; Yonehara, S.; Ishii, A.; Yonehara, M.; Mizushima, S.-I.; Sameshima, M.; Hase, A.; Seto, Y.; Nagata, S. The polypeptide encoded by the cDNA for human cell surface antigen Fas can mediate apoptosis. Cell 1991, 66, 233-243, doi:https://doi.org/10.1016/0092-8674(91)90614-5.

47. Suda, T.; Takahashi, T.; Golstein, P.; Nagata, S. Molecular cloning and expression of the fas ligand, a novel member of the tumor necrosis factor family. Cell 1993, 75, 1169-1178, doi:https://doi.org/10.1016/0092$\underline{8674(93) 90326-\mathrm{L}}$.

48. Chinnaiyan, A.M.; O'Rourke, K.; Tewari, M.; Dixit, V.M. FADD, a novel death domain-containing protein, interacts with the death domain of fas and initiates apoptosis. Cell 1995, 81, 505-512, doi:https://doi.org/10.1016/0092-8674(95)90071-3. 
49. Thome, M.; Tschopp, J. TCR-induced NF-kappaB activation: a crucial role for Carma1, Bcl10 and MALT1. Trends Immunol. 2003, 24, 419-424, doi:10.1016/s1471-4906(03)00177-7.

50. Vallabhapurapu, S.; Karin, M. Regulation and function of NF-kappaB transcription factors in the immune system. Annu. Rev. Immunol. 2009, 27, 693-733, doi:10.1146/annurev.immunol.021908.132641.

51. Li, H.; Zhu, H.; Xu, C.J.; Yuan, J. Cleavage of BID by caspase 8 mediates the mitochondrial damage in the Fas pathway of apoptosis. Cell 1998, 94, 491-501, doi:10.1016/s0092-8674(00)81590-1.

52. Grinberg, M.; Schwarz, M.; Zaltsman, Y.; Eini, T.; Niv, H.; Pietrokovski, S.; Gross, A. Mitochondrial carrier homolog 2 is a target of tBID in cells signaled to die by tumor necrosis factor alpha. Mol. Cell. Biol. 2005, 25, 4579-4590, doi:10.1128/mcb.25.11.4579-4590.2005.

53. Akashi, K.; Kondo, M.; von Freeden-Jeffry, U.; Murray, R.; Weissman, I.L. Bcl-2 Rescues T Lymphopoiesis in Interleukin-7 Receptor-Deficient Mice. Cell 1997, 89, 1033-1041, doi:https://doi.org/10.1016/S00928674(00)80291-3.

54. Maraskovsky, E.; O'Reilly, L.A.; Teepe, M.; Corcoran, L.M.; Peschon, J.J.; Strasser, A. Bcl-2 Can Rescue T Lymphocyte Development in Interleukin-7 Receptor-Deficient Mice but Not in Mutant rag-1-/- Mice. Cell 1997, 89, 1011-1019, doi:https://doi.org/10.1016/S0092-8674(00)80289-5.

55. Bouillet, P.; O'Reilly, L.A. CD95, BIM and T cell homeostasis. Nature Reviews Immunology 2009, 9, 514-519, doi:10.1038/nri2570.

56. Hughes, P.D.; Belz, G.T.; Fortner, K.A.; Budd, R.C.; Strasser, A.; Bouillet, P. Apoptosis Regulators Fas and Bim Cooperate in Shutdown of Chronic Immune Responses and Prevention of Autoimmunity. Immunity 2008, 28, 197-205, doi:https://doi.org/10.1016/j.immuni.2007.12.017.

57. Craddock, J.; Heslop, H.E. Adoptive cellular therapy with T cells specific for EBV-derived tumor antigens. Update Cancer Ther. 2008, 3, 33-41, doi:10.1016/j.uct.2008.01.001.

58. Houghtelin, A.; Bollard, C.M. Virus-Specific T Cells for the Immunocompromised Patient. Front. Immunol. 2017, 8, 1272, doi:10.3389/fimmu.2017.01272.

59. Heslop, H.E.; Slobod, K.S.; Pule, M.A.; Hale, G.A.; Rousseau, A.; Smith, C.A.; Bollard, C.M.; Liu, H.; Wu, M.F.; Rochester, R.J., et al. Long-term outcome of EBV-specific T-cell infusions to prevent or treat EBV-related lymphoproliferative disease in transplant recipients. Blood 2010, 115, 925-935, doi:10.1182/blood-2009-08239186.

60. Walter, E.A.; Greenberg, P.D.; Gilbert, M.J.; Finch, R.J.; Watanabe, K.S.; Thomas, E.D.; Riddell, S.R. Reconstitution of cellular immunity against cytomegalovirus in recipients of allogeneic bone marrow by transfer of T-cell clones from the donor. N. Engl. J. Med. 1995, 333, 1038-1044,

doi:10.1056/nejm199510193331603.

61. Doubrovina, E.; Oflaz-Sozmen, B.; Prockop, S.E.; Kernan, N.A.; Abramson, S.; Teruya-Feldstein, J.; Hedvat, C.; Chou, J.F.; Heller, G.; Barker, J.N., et al. Adoptive immunotherapy with unselected or EBV-specific T cells for biopsy-proven EBV+ lymphomas after allogeneic hematopoietic cell transplantation. Blood 2012, 119, 26442656, doi:10.1182/blood-2011-08-371971.

62. Gerdemann, U.; Keirnan, J.M.; Katari, U.L.; Yanagisawa, R.; Christin, A.S.; Huye, L.E.; Perna, S.K.; Ennamuri, S.; Gottschalk, S.; Brenner, M.K., et al. Rapidly generated multivirus-specific cytotoxic T lymphocytes for the prophylaxis and treatment of viral infections. Mol. Ther. 2012, 20, 1622-1632, doi:10.1038/mt.2012.130.

63. Icheva, V.; Kayser, S.; Wolff, D.; Tuve, S.; Kyzirakos, C.; Bethge, W.; Greil, J.; Albert, M.H.; Schwinger, W.; Nathrath, M., et al. Adoptive transfer of epstein-barr virus (EBV) nuclear antigen 1-specific $t$ cells as treatment 
for EBV reactivation and lymphoproliferative disorders after allogeneic stem-cell transplantation. J. Clin. Oncol. 2013, 31, 39-48, doi:10.1200/jco.2011.39.8495.

64. Hanley, P.J.; Melenhorst, J.J.; Nikiforow, S.; Scheinberg, P.; Blaney, J.W.; Demmler-Harrison, G.; Cruz, C.R.; Lam, S.; Krance, R.A.; Leung, K.S., et al. CMV-specific T cells generated from naïve T cells recognize atypical epitopes and may be protective in vivo. Sci. Transl. Med. 2015, 7, 285ra263, doi:10.1126/scitranslmed.aaa2546.

65. Boudreau, G.; Carli, C.; Lamarche, C.; Rulleau, C.; Bonnaure, G.; Néron, S.; Delisle, J.-S. Leukoreduction system chambers are a reliable cellular source for the manufacturing of T-cell therapeutics. Transfusion 2019, 59, 1300-1311, doi:10.1111/trf.15121.

66. Chapuis, A.G.; Ragnarsson, G.B.; Nguyen, H.N.; Chaney, C.N.; Pufnock, J.S.; Schmitt, T.M.; Duerkopp, N.; Roberts, I.M.; Pogosov, G.L.; Ho, W.Y., et al. Transferred WT1-reactive CD8+ T cells can mediate antileukemic activity and persist in post-transplant patients. Sci. Transl. Med. 2013, 5, 174ra127, doi:10.1126/scitranslmed.3004916.

67. Warren, E.H.; Fujii, N.; Akatsuka, Y.; Chaney, C.N.; Mito, J.K.; Loeb, K.R.; Gooley, T.A.; Brown, M.L.; Koo, K.K.W.; Rosinski, K.V., et al. Therapy of relapsed leukemia after allogeneic hematopoietic cell transplantation with T cells specific for minor histocompatibility antigens. Blood 2010, 115, 3869-3878.

68. Meij, P.; Jedema, I.; van der Hoorn, M.A.; Bongaerts, R.; Cox, L.; Wafelman, A.R.; Marijt, E.W.A.; Willemze, R.; Falkenburg, J.H.F. Generation and administration of HA-1-specific T-cell lines for the treatment of patients with relapsed leukemia after allogeneic stem cell transplantation: a pilot study. Haematologica 2012, 97, 12051208.

69. Granados, D.P.; Rodenbrock, A.; Laverdure, J.P.; Côté, C.; Caron-Lizotte, O.; Carli, C.; Pearson, H.; Janelle, V.; Durette, C.; Bonneil, E., et al. Proteogenomic-based discovery of minor histocompatibility antigens with suitable features for immunotherapy of hematologic cancers. Leukemia 2016, 30, 1344, doi:10.1038/leu.2016.22 https://www.nature.com/articles/leu201622\#supplementary-information.

70. Roopenian, D.; Choi, E.Y.; Brown, A. The immunogenomics of minor histocompatibility antigens. Immunol. Rev. 2002, 190, 86-94, doi:10.1034/j.1600-065X.2002.19007.x.

71. Mullally, A.; Ritz, J. Beyond HLA: the significance of genomic variation for allogeneic hematopoietic stem cell transplantation. Blood 2007, 109, 1355-1362, doi:10.1182/blood-2006-06-030858.

72. Zilberberg, J.; Feinman, R.; Korngold, R. Strategies for the identification of T cell-recognized tumor antigens in hematological malignancies for improved graft-versus-tumor responses after allogeneic blood and marrow transplantation. Biol. Blood Marrow Transplant. 2015, 21, 1000-1007, doi:10.1016/j.bbmt.2014.11.001.

73. Gattinoni, L.; Klebanoff, C.A.; Palmer, D.C.; Wrzesinski, C.; Kerstann, K.; Yu, Z.; Finkelstein, S.E.; Theoret, M.R.; Rosenberg, S.A.; Restifo, N.P. Acquisition of full effector function in vitro paradoxically impairs the in vivo antitumor efficacy of adoptively transferred CD8+ T cells. J. Clin. Invest. 2005, 115, 1616-1626, doi:10.1172/JCI24480.

74. Gattinoni, L.; Klebanoff, C.A.; Restifo, N.P. Paths to stemness: building the ultimate antitumour T cell. Nat. Rev. Cancer 2012, 12, 671-684.

75. June, C.H.; Riddell, S.R.; Schumacher, T.N. Adoptive cellular therapy: A race to the finish line. Sci. Transl. Med. 2015, 7, 280-287, doi:10.1126/scitranslmed.aaa3643.

76. Dahmani, A.; Janelle, V.; Carli, C.; Richaud, M.; Lamarche, C.; Khalili, M.; Goupil, M.; Bezverbnaya, K.; Bramson, J.L.; Delisle, J.S. TGF $\beta$ Programs Central Memory Differentiation in Ex Vivo-Stimulated Human T Cells. Cancer Immunol Res 2019, 7, 1426-1439, doi:10.1158/2326-6066.cir-18-0691. 
77. Orio, J.; Carli, C.; Janelle, V.; Giroux, M.; Taillefer, J.; Goupil, M.; Richaud, M.; Roy, D.-C.; Delisle, J.-S. Early exposure to interleukin-21 limits rapidly generated anti-Epstein-Barr virus T-cell line differentiation. Cytotherapy 2015, 17, 496-508, doi:http://dx.doi.org/10.1016/j.jcyt.2014.12.009.

78. Wang, J.; Hasan, F.; Frey, A.C.; Li, H.S.; Park, J.; Pan, K.; Haymaker, C.; Bernatchez, C.; Lee, D.A.; Watowich, S.S., et al. Histone Deacetylase Inhibitors and IL21 Cooperate to Reprogram Human Effector CD8\&lt;sup\&gt;+\&lt;/sup\&gt; T Cells to Memory T Cells. Cancer Immunol Res 2020, 8, 794, doi:10.1158/23266066.CIR-19-0619.

79. $\quad$ van der Waart, A.B.; van de Weem, N.M.P.; Maas, F.; Kramer, C.S.M.; Kester, M.G.D.; Falkenburg, J.H.F.; Schaap, N.; Jansen, J.H.; van der Voort, R.; Gattinoni, L., et al. Inhibition of Akt signaling promotes the generation of superior tumor-reactive T cells for adoptive immunotherapy. Blood 2014, 124, 3490-3500, doi:10.1182/blood-2014-05-578583.

80. Chapuis, A.G.; Thompson, J.A.; Margolin, K.A.; Rodmyre, R.; Lai, I.P.; Dowdy, K.; Farrar, E.A.; Bhatia, S.; Sabath, D.E.; Cao, J., et al. Transferred melanoma-specific CD8\&lt;sup\&gt;+\&lt;/sup\&gt; T cells persist, mediate tumor regression, and acquire central memory phenotype. Proceedings of the National Academy of Sciences 2012, 109, 4592, doi:10.1073/pnas.1113748109.

81. Nishimura, T.; Kaneko, S.; Kawana-Tachikawa, A.; Tajima, Y.; Goto, H.; Zhu, D.; Nakayama-Hosoya, K.; Iriguchi, S.; Uemura, Y.; Shimizu, T., et al. Generation of rejuvenated antigen-specific T cells by reprogramming to pluripotency and redifferentiation. Cell stem cell 2013, 12, 114-126, doi:10.1016/j.stem.2012.11.002.

82. Kennedy, M.; Awong, G.; Sturgeon, C.M.; Ditadi, A.; LaMotte-Mohs, R.; Zúñiga-Pflücker, J.C.; Keller, G. T lymphocyte potential marks the emergence of definitive hematopoietic progenitors in human pluripotent stem cell differentiation cultures. Cell Rep 2012, 2, 1722-1735, doi:10.1016/j.celrep.2012.11.003.

83. Vizcardo, R.; Masuda, K.; Yamada, D.; Ikawa, T.; Shimizu, K.; Fujii, S.; Koseki, H.; Kawamoto, H. Regeneration of human tumor antigen-specific T cells from iPSCs derived from mature CD8(+) T cells. Cell stem cell 2013, 12, 31-36, doi:10.1016/j.stem.2012.12.006.

84. Kim, K.; Doi, A.; Wen, B.; Ng, K.; Zhao, R.; Cahan, P.; Kim, J.; Aryee, M.J.; Ji, H.; Ehrlich, L.I.R., et al. Epigenetic memory in induced pluripotent stem cells. Nature 2010, 467, 285-290, doi:10.1038/nature09342.

85. Ando, M.; Nishimura, T.; Yamazaki, S.; Yamaguchi, T.; Kawana-Tachikawa, A.; Hayama, T.; Nakauchi, Y.; Ando, J.; Ota, Y.; Takahashi, S., et al. A Safeguard System for Induced Pluripotent Stem Cell-Derived Rejuvenated T Cell Therapy. Stem cell reports 2015, 5, 597-608, doi:10.1016/j.stemcr.2015.07.011.

86. Timmermans, F.; Velghe, I.; Vanwalleghem, L.; De Smedt, M.; Van Coppernolle, S.; Taghon, T.; Moore, H.D.; Leclercq, G.; Langerak, A.W.; Kerre, T., et al. Generation of T Cells from Human Embryonic Stem CellDerived Hematopoietic Zones. The Journal of Immunology 2009, 182, 6879, doi:10.4049/jimmunol.0803670.

87. Chan, J.; Kim, P.Y.; Kranz, E.; Nagaoka, Y.; Lee, Y.; Wen, J.; Elsaesser, H.J.; Qin, M.; Brooks, D.G.; Ringpis, G.E., et al. Purging Exhausted Virus-Specific CD8 T Cell Phenotypes by Somatic Cell Reprogramming. AIDS Res. Hum. Retroviruses 2017, 33, S59-s69, doi:10.1089/aid.2017.0161.

88. Tanaka, Y.; Murata-Hirai, K.; Iwasaki, M.; Matsumoto, K.; Hayashi, K.; Kumagai, A.; Nada, M.H.; Wang, H.; Kobayashi, H.; Kamitakahara, H., et al. Expansion of human $\gamma \delta \mathrm{T}$ cells for adoptive immunotherapy using a bisphosphonate prodrug. Cancer Sci. 2018, 109, 587-599, doi:10.1111/cas.13491.

89. Hoeres, T.; Smetak, M.; Pretscher, D.; Wilhelm, M. Improving the Efficiency of V $\gamma 9 \mathrm{~V} \delta 2$ T-Cell Immunotherapy in Cancer. Front. Immunol. 2018, 9, 800-800, doi:10.3389/fimmu.2018.00800. 
90. Paul, S.; Lal, G. Regulatory and effector functions of gamma-delta $(\gamma \delta)$ T cells and their therapeutic potential in adoptive cellular therapy for cancer. Int. J. Cancer 2016, 139, 976-985, doi:10.1002/ijc.30109.

91. Nada, M.H.; Wang, H.; Workalemahu, G.; Tanaka, Y.; Morita, C.T. Enhancing adoptive cancer immunotherapy with V $\gamma 2 \mathrm{~V} \delta 2 \mathrm{~T}$ cells through pulse zoledronate stimulation. J Immunother Cancer 2017, 5, 9, doi:10.1186/s40425-017-0209-6.

92. Zumwalde, N.A.; Sharma, A.; Xu, X.; Ma, S.; Schneider, C.L.; Romero-Masters, J.C.; Hudson, A.W.; GendronFitzpatrick, A.; Kenney, S.C.; Gumperz, J.E. Adoptively transferred V $\gamma 9 \mathrm{~V} \delta 2 \mathrm{~T}$ cells show potent antitumor effects in a preclinical B cell lymphomagenesis model. JCI Insight 2017, 2, doi:10.1172/jci.insight.93179.

93. Kronenberg, M. When less is more: T lymphocyte populations with restricted antigen receptor diversity. J. Immunol. 2014, 193, 975-976, doi:10.4049/jimmunol.1401491.

94. Van Rhijn, I.; Moody, D.B. Donor Unrestricted T Cells: A Shared Human T Cell Response. J. Immunol. 2015, 195, 1927-1932, doi:10.4049/jimmunol.1500943.

95. Salio, M.; Silk, J.D.; Jones, E.Y.; Cerundolo, V. Biology of CD1- and MR1-restricted T cells. Annu. Rev. Immunol. 2014, 32, 323-366, doi:10.1146/annurev-immunol-032713-120243.

96. Constantinides, M.G.; Bendelac, A. Transcriptional regulation of the NKT cell lineage. Curr. Opin. Immunol. 2013, 25, 161-167, doi:10.1016/j.coi.2013.01.003.

97. Brennan, P.J.; Brigl, M.; Brenner, M.B. Invariant natural killer T cells: an innate activation scheme linked to diverse effector functions. Nat. Rev. Immunol. 2013, 13, 101-117, doi:10.1038/nri3369.

98. Brossay, L.; Chioda, M.; Burdin, N.; Koezuka, Y.; Casorati, G.; Dellabona, P.; Kronenberg, M. CD1d-mediated recognition of an alpha-galactosylceramide by natural killer $\mathrm{T}$ cells is highly conserved through mammalian evolution. J. Exp. Med. 1998, 188, 1521-1528, doi:10.1084/jem.188.8.1521.

99. Exley, M.A.; Lynch, L.; Varghese, B.; Nowak, M.; Alatrakchi, N.; Balk, S.P. Developing understanding of the roles of CD1d-restricted T cell subsets in cancer: reversing tumor-induced defects. Clin. Immunol. 2011, 140, 184-195, doi:10.1016/j.clim.2011.04.017.

100. Motohashi, S.; Ishikawa, A.; Ishikawa, E.; Otsuji, M.; Iizasa, T.; Hanaoka, H.; Shimizu, N.; Horiguchi, S.; Okamoto, Y.; Fujii, S., et al. A phase I study of in vitro expanded natural killer T cells in patients with advanced and recurrent non-small cell lung cancer. Clin. Cancer. Res. 2006, 12, 6079-6086, doi:10.1158/10780432.ccr-06-0114.

101. Kunii, N.; Horiguchi, S.; Motohashi, S.; Yamamoto, H.; Ueno, N.; Yamamoto, S.; Sakurai, D.; Taniguchi, M.; Nakayama, T.; Okamoto, Y. Combination therapy of in vitro-expanded natural killer T cells and alphagalactosylceramide-pulsed antigen-presenting cells in patients with recurrent head and neck carcinoma. Cancer Sci. 2009, 100, 1092-1098, doi:10.1111/j.1349-7006.2009.01135.x.

102. Yamasaki, K.; Horiguchi, S.; Kurosaki, M.; Kunii, N.; Nagato, K.; Hanaoka, H.; Shimizu, N.; Ueno, N.; Yamamoto, S.; Taniguchi, M., et al. Induction of NKT cell-specific immune responses in cancer tissues after NKT cell-targeted adoptive immunotherapy. Clin. Immunol. 2011, 138, 255-265, doi:10.1016/j.clim.2010.11.014.

103. Exley, M.A.; Friedlander, P.; Alatrakchi, N.; Vriend, L.; Yue, S.; Sasada, T.; Zeng, W.; Mizukami, Y.; Clark, J.; Nemer, D., et al. Adoptive Transfer of Invariant NKT Cells as Immunotherapy for Advanced Melanoma: A Phase I Clinical Trial. Clin. Cancer. Res. 2017, 23, 3510-3519, doi:10.1158/1078-0432.ccr-16-0600.

104. Exley, M.A.; Hou, R.; Shaulov, A.; Tonti, E.; Dellabona, P.; Casorati, G.; Akbari, O.; Akman, H.O.; Greenfield, E.A.; Gumperz, J.E., et al. Selective activation, expansion, and monitoring of human iNKT cells with a monoclonal antibody specific for the TCR alpha-chain CDR3 loop. Eur. J. Immunol. 2008, 38, 1756-1766, doi:10.1002/eji.200737389. 
105. Exley, M.A.; Wilson, S.B.; Balk, S.P. Isolation and Functional Use of Human NKT Cells. Curr. Protoc. Immunol. 2017, 119, 14.11.11-14.11.20, doi:10.1002/cpim.33.

106. Pillai, A.B.; George, T.I.; Dutt, S.; Teo, P.; Strober, S. Host NKT Cells Can Prevent Graft-versus-Host Disease and Permit Graft Antitumor Activity after Bone Marrow Transplantation. The Journal of Immunology 2007, 178, 6242, doi:10.4049/jimmunol.178.10.6242.

107. Wolf, B.J.; Choi, J.E.; Exley, M.A. Novel Approaches to Exploiting Invariant NKT Cells in Cancer Immunotherapy. Front. Immunol. 2018, 9, 384-384, doi:10.3389/fimmu.2018.00384.

108. Chiossone, L.; Dumas, P.-Y.; Vienne, M.; Vivier, E. Natural killer cells and other innate lymphoid cells in cancer. Nature Reviews Immunology 2018, 18, 671-688, doi:10.1038/s41577-018-0061-z.

109. Artis, D.; Spits, H. The biology of innate lymphoid cells. Nature 2015, 517, 293-301, doi:10.1038/nature14189.

110. Serafini, N.; Vosshenrich, C.A.; Di Santo, J.P. Transcriptional regulation of innate lymphoid cell fate. Nat. Rev. Immunol. 2015, 15, 415-428, doi:10.1038/nri3855.

111. Fuchs, A.; Vermi, W.; Lee, J.S.; Lonardi, S.; Gilfillan, S.; Newberry, R.D.; Cella, M.; Colonna, M. Intraepithelial type 1 innate lymphoid cells are a unique subset of IL-12- and IL-15-responsive IFN- $\gamma$-producing cells. Immunity 2013, 38, 769-781, doi:10.1016/j.immuni.2013.02.010.

112. Bernink, J.H.; Peters, C.P.; Munneke, M.; te Velde, A.A.; Meijer, S.L.; Weijer, K.; Hreggvidsdottir, H.S.; Heinsbroek, S.E.; Legrand, N.; Buskens, C.J., et al. Human type 1 innate lymphoid cells accumulate in inflamed mucosal tissues. Nat. Immunol. 2013, 14, 221-229, doi:10.1038/ni.2534.

113. Gerbe, F.; Sidot, E.; Smyth, D.J.; Ohmoto, M.; Matsumoto, I.; Dardalhon, V.; Cesses, P.; Garnier, L.; Pouzolles, M.; Brulin, B., et al. Intestinal epithelial tuft cells initiate type 2 mucosal immunity to helminth parasites. Nature 2016, 529, 226-230, doi:10.1038/nature16527.

114. Wallrapp, A.; Riesenfeld, S.J.; Burkett, P.R.; Abdulnour, R.E.; Nyman, J.; Dionne, D.; Hofree, M.; Cuoco, M.S.; Rodman, C.; Farouq, D., et al. The neuropeptide NMU amplifies ILC2-driven allergic lung inflammation. Nature 2017, 549, 351-356, doi:10.1038/nature24029.

115. Buonocore, S.; Ahern, P.P.; Uhlig, H.H.; Ivanov, II; Littman, D.R.; Maloy, K.J.; Powrie, F. Innate lymphoid cells drive interleukin-23-dependent innate intestinal pathology. Nature 2010, 464, 1371-1375, doi:10.1038/nature08949.

116. Ibiza, S.; García-Cassani, B.; Ribeiro, H.; Carvalho, T.; Almeida, L.; Marques, R.; Misic, A.M.; BartowMcKenney, C.; Larson, D.M.; Pavan, W.J., et al. Glial-cell-derived neuroregulators control type 3 innate lymphoid cells and gut defence. Nature 2016, 535, 440-443, doi:10.1038/nature18644.

117. Withers, D.R. Lymphoid tissue inducer cells. Curr. Biol. 2011, 21, R381-R382, doi:https://doi.org/10.1016/j.cub.2011.03.022.

118. Vivier, E.; Artis, D.; Colonna, M.; Diefenbach, A.; Di Santo, J.P.; Eberl, G.; Koyasu, S.; Locksley, R.M.; McKenzie, A.N.J.; Mebius, R.E., et al. Innate Lymphoid Cells: 10 Years On. Cell 2018, 174, 1054-1066, doi:https://doi.org/10.1016/j.cell.2018.07.017.

119. Böttcher, J.P.; Bonavita, E.; Chakravarty, P.; Blees, H.; Cabeza-Cabrerizo, M.; Sammicheli, S.; Rogers, N.C.; Sahai, E.; Zelenay, S.; Reis E Sousa, C. NK Cells Stimulate Recruitment of cDC1 into the Tumor Microenvironment Promoting Cancer Immune Control. Cell 2018, 172, 1022-1037.e1014, doi:10.1016/j.cell.2018.01.004.

120. Pallmer, K.; Oxenius, A. Recognition and Regulation of T Cells by NK Cells. Front. Immunol. 2016, 7, 251-251, doi:10.3389/fimmu.2016.00251. 
121. Zhang, Q.; Bi, J.; Zheng, X.; Chen, Y.; Wang, H.; Wu, W.; Wang, Z.; Wu, Q.; Peng, H.; Wei, H., et al. Blockade of the checkpoint receptor TIGIT prevents NK cell exhaustion and elicits potent anti-tumor immunity. Nat. Immunol. 2018, 19, 723-732, doi:10.1038/s41590-018-0132-0.

122. Bi, J.; Tian, Z. NK Cell Exhaustion. Front. Immunol. 2017, 8, 760, doi:10.3389/fimmu.2017.00760.

123. Lim, O.; Lee, Y.; Chung, H.; Her, J.H.; Kang, S.M.; Jung, M.-y.; Min, B.; Shin, H.; Kim, T.M.; Heo, D.S., et al. GMP-compliant, large-scale expanded allogeneic natural killer cells have potent cytolytic activity against cancer cells in vitro and in vivo. PLoS One 2013, 8, e53611-e53611, doi:10.1371/journal.pone.0053611.

124. Torelli, G.F.; Rozera, C.; Santodonato, L.; Peragine, N.; D'Agostino, G.; Montefiore, E.; Napolitano, M.R.; Monque, D.M.; Carlei, D.; Mariglia, P., et al. A good manufacturing practice method to ex vivo expand natural killer cells for clinical use. Blood Transfus. 2015, 13, 464-471, doi:10.2450/2015.0231-14.

125. Alici, E.; Sutlu, T.; Björkstrand, B.; Gilljam, M.; Stellan, B.; Nahi, H.; Quezada, H.C.; Gahrton, G.; Ljunggren, H.G.; Dilber, M.S. Autologous antitumor activity by NK cells expanded from myeloma patients using GMPcompliant components. Blood 2008, 111, 3155-3162, doi:10.1182/blood-2007-09-110312.

126. Koehl, U.; Brehm, C.; Huenecke, S.; Zimmermann, S.Y.; Kloess, S.; Bremm, M.; Ullrich, E.; Soerensen, J.; Quaiser, A.; Erben, S., et al. Clinical grade purification and expansion of NK cell products for an optimized manufacturing protocol. Front. Oncol. 2013, 3, 118, doi:10.3389/fonc.2013.00118.

127. Ortaldo, J.R.; Winkler-Pickett, R.; Wigginton, J.; Horner, M.; Bere, E.W.; Mason, A.T.; Bhat, N.; Cherry, J.; Sanford, M.; Hodge, D.L., et al. Regulation of ITAM-positive receptors: role of IL-12 and IL-18. Blood 2006, 107, 1468-1475, doi:10.1182/blood-2005-04-1579.

128. Burgess, S.J.; Marusina, A.I.; Pathmanathan, I.; Borrego, F.; Coligan, J.E. IL-21 down-regulates NKG2D/DAP10 expression on human NK and CD8+ T cells. J. Immunol. 2006, 176, 1490-1497, doi:10.4049/jimmunol.176.3.1490.

129. Becknell, B.; Caligiuri, M.A. Interleukin-2, interleukin-15, and their roles in human natural killer cells. Adv. Immunol. 2005, 86, 209-239, doi:10.1016/s0065-2776(04)86006-1.

130. Colombo, M.P.; Trinchieri, G. Interleukin-12 in anti-tumor immunity and immunotherapy. Cytokine Growth Factor Rev. 2002, 13, 155-168, doi:10.1016/s1359-6101(01)00032-6.

131. Moretta, A.; Bottino, C.; Vitale, M.; Pende, D.; Cantoni, C.; Mingari, M.C.; Biassoni, R.; Moretta, L. Activating receptors and coreceptors involved in human natural killer cell-mediated cytolysis. Annu. Rev. Immunol. 2001, 19, 197-223, doi:10.1146/annurev.immunol.19.1.197.

132. Huenecke, S.; Zimmermann, S.Y.; Kloess, S.; Esser, R.; Brinkmann, A.; Tramsen, L.; Koenig, M.; Erben, S.; Seidl, C.; Tonn, T., et al. IL-2-driven regulation of NK cell receptors with regard to the distribution of CD16+ and CD16- subpopulations and in vivo influence after haploidentical NK cell infusion. J. Immunother. 2010, 33, 200-210, doi:10.1097/CJI.0b013e3181bb46f7.

133. Wang, K.S.; Frank, D.A.; Ritz, J. Interleukin-2 enhances the response of natural killer cells to interleukin-12 through up-regulation of the interleukin-12 receptor and STAT4. Blood 2000, 95, 3183-3190.

134. Mao, Y.; van Hoef, V.; Zhang, X.; Wennerberg, E.; Lorent, J.; Witt, K.; Masvidal, L.; Liang, S.; Murray, S.; Larsson, O., et al. IL-15 activates mTOR and primes stress-activated gene expression leading to prolonged antitumor capacity of NK cells. Blood 2016, 128, 1475-1489, doi:10.1182/blood-2016-02-698027.

135. Fehniger, T.A.; Cooper, M.A.; Caligiuri, M.A. Interleukin-2 and interleukin-15: immunotherapy for cancer. Cytokine Growth Factor Rev. 2002, 13, 169-183, doi:10.1016/s1359-6101(01)00021-1.

136. Waldmann, T.A. The biology of interleukin-2 and interleukin-15: implications for cancer therapy and vaccine design. Nat. Rev. Immunol. 2006, 6, 595-601, doi:10.1038/nri1901. 
137. Felices, M.; Lenvik, A.; Chu, S.; McElmurry, R.; Cooley, S.; Tolar, J.; Blazar, B.R.; Miller, J.S. Continuous IL-15 Signaling Leads to Functional Exhaustion of Human Natural Killer Cells through Metabolic Changes That Alters Their In Vivo Anti-Tumor Activity. Blood 2016, 128, 551-551, doi:10.1182/blood.V128.22.551.551.

138. French, A.R.; Holroyd, E.B.; Yang, L.; Kim, S.; Yokoyama, W.M. IL-18 acts synergistically with IL-15 in stimulating natural killer cell proliferation. Cytokine 2006, 35, 229-234, doi:10.1016/j.cyto.2006.08.006.

139. Chaix, J.; Tessmer, M.S.; Hoebe, K.; Fuséri, N.; Ryffel, B.; Dalod, M.; Alexopoulou, L.; Beutler, B.; Brossay, L.; Vivier, E., et al. Cutting edge: Priming of NK cells by IL-18. J. Immunol. 2008, 181, 1627-1631, doi:10.4049/jimmunol.181.3.1627.

140. McMichael, E.L.; Jaime-Ramirez, A.C.; Guenterberg, K.D.; Luedke, E.; Atwal, L.S.; Campbell, A.R.; Hu, Z.; Tatum, A.S.; Kondadasula, S.V.; Mo, X., et al. IL-21 Enhances Natural Killer Cell Response to CetuximabCoated Pancreatic Tumor Cells. Clin. Cancer. Res. 2017, 23, 489-502, doi:10.1158/1078-0432.ccr-16-0004.

141. Iannello, A.; Boulassel, M.-R.; Samarani, S.; Tremblay, C.; Toma, E.; Routy, J.-P.; Ahmad, A. IL-21 enhances NK cell functions and survival in healthy and HIV-infected patients with minimal stimulation of viral replication. J. Leukoc. Biol. 2010, 87, 857-867, doi:https://doi.org/10.1189/jlb.1009701.

142. Kasaian, M.T.; Whitters, M.J.; Carter, L.L.; Lowe, L.D.; Jussif, J.M.; Deng, B.; Johnson, K.A.; Witek, J.S.; Senices, M.; Konz, R.F., et al. IL-21 limits NK cell responses and promotes antigen-specific T cell activation: a mediator of the transition from innate to adaptive immunity. Immunity 2002, 16, 559-569, doi:10.1016/s10747613(02)00295-9.

143. Li, Q.; Ye, L.J.; Ren, H.L.; Huyan, T.; Li, J.; Shi, J.L.; Huang, Q.S. Multiple effects of IL-21 on human NK cells in ex vivo expansion. Immunobiology 2015, 220, 876-888, doi:10.1016/j.imbio.2015.01.009.

144. Granzin, M.; Stojanovic, A.; Miller, M.; Childs, R.; Huppert, V.; Cerwenka, A. Highly efficient IL-21 and feeder cell-driven ex vivo expansion of human NK cells with therapeutic activity in a xenograft mouse model of melanoma. Oncoimmunology 2016, 5, e1219007, doi:10.1080/2162402x.2016.1219007.

145. Lim, D.P.; Jang, Y.Y.; Kim, S.; Koh, S.S.; Lee, J.J.; Kim, J.S.; Thi Phan, M.T.; Shin, D.J.; Shin, M.G.; Lee, S.H., et al. Effect of exposure to interleukin-21 at various time points on human natural killer cell culture. Cytotherapy 2014, 16, 1419-1430, doi:10.1016/j.jcyt.2014.04.008.

146. Hsu, J.; Hodgins, J.J.; Marathe, M.; Nicolai, C.J.; Bourgeois-Daigneault, M.-C.; Trevino, T.N.; Azimi, C.S.; Scheer, A.K.; Randolph, H.E.; Thompson, T.W., et al. Contribution of NK cells to immunotherapy mediated by PD-1/PD-L1 blockade. The Journal of clinical investigation 2018, 128, 4654-4668, doi:10.1172/JCI99317.

147. Geller, M.A.; Cooley, S.; Judson, P.L.; Ghebre, R.; Carson, L.F.; Argenta, P.A.; Jonson, A.L.; PanoskaltsisMortari, A.; Curtsinger, J.; McKenna, D., et al. A phase II study of allogeneic natural killer cell therapy to treat patients with recurrent ovarian and breast cancer. Cytotherapy 2011, 13, 98-107, doi:10.3109/14653249.2010.515582.

148. Inozume, T.; Hanada, K.; Wang, Q.J.; Ahmadzadeh, M.; Wunderlich, J.R.; Rosenberg, S.A.; Yang, J.C. Selection of CD8+PD-1+ lymphocytes in fresh human melanomas enriches for tumor-reactive T cells. J. Immunother. 2010, 33, 956-964, doi:10.1097/CJI.0b013e3181fad2b0.

149. Yang, S.; Ji, Y.; Gattinoni, L.; Zhang, L.; Yu, Z.; Restifo, N.P.; Rosenberg, S.A.; Morgan, R.A. Modulating the differentiation status of ex vivo-cultured anti-tumor T cells using cytokine cocktails. Cancer Immunol. Immunother. 2013, 62, 727-736, doi:10.1007/s00262-012-1378-2.

150. Li, Y.; Liu, S.; Hernandez, J.; Vence, L.; Hwu, P.; Radvanyi, L. MART-1-specific melanoma tumor-infiltrating lymphocytes maintaining CD28 expression have improved survival and expansion capability following antigenic restimulation in vitro. J. Immunol. 2010, 184, 452-465, doi:10.4049/jimmunol.0901101. 
151. van den Berg, J.H.; Heemskerk, B.; van Rooij, N.; Gomez-Eerland, R.; Michels, S.; van Zon, M.; de Boer, R.; Bakker, N.A.M.; Jorritsma-Smit, A.; van Buuren, M.M., et al. Tumor infiltrating lymphocytes (TIL) therapy in metastatic melanoma: boosting of neoantigen-specific T cell reactivity and long-term follow-up. J Immunother Cancer 2020, 8, doi:10.1136/jitc-2020-000848.

152. Jansen, C.S.; Prokhnevska, N.; Master, V.A.; Sanda, M.G.; Carlisle, J.W.; Bilen, M.A.; Cardenas, M.; Wilkinson, S.; Lake, R.; Sowalsky, A.G., et al. An intra-tumoral niche maintains and differentiates stem-like CD8 T cells. Nature 2019, 576, 465-470, doi:10.1038/s41586-019-1836-5.

153. Brien, S.M.; Klampatsa, A.; Thompson, J.C.; Martinez, M.C.; Hwang, W.-T.; Rao, A.S.; Standalick, J.E.; Kim, S.; Cantu, E.; Litzky, L.A., et al. Function of Human Tumor-Infiltrating Lymphocytes in Early-Stage Non-Small Cell Lung Cancer. Cancer Immunol Res 2019, 7, 896, doi:10.1158/2326-6066.CIR-18-0713.

154. Kumar, B.V.; Ma, W.; Miron, M.; Granot, T.; Guyer, R.S.; Carpenter, D.J.; Senda, T.; Sun, X.; Ho, S.-H.; Lerner, H., et al. Human Tissue-Resident Memory T Cells Are Defined by Core Transcriptional and Functional Signatures in Lymphoid and Mucosal Sites. Cell Rep 2017, 20, 2921-2934, doi:10.1016/j.celrep.2017.08.078.

155. Li, C.; Zhu, B.; Son, Y.M.; Wang, Z.; Jiang, L.; Xiang, M.; Ye, Z.; Beckermann, K.E.; Wu, Y.; Jenkins, J.W., et al. The Transcription Factor Bhlhe40 Programs Mitochondrial Regulation of Resident CD8(+) T Cell Fitness and Functionality. Immunity 2019, 51, 491-507.e497, doi:10.1016/j.immuni.2019.08.013.

156. Woroniecka, K.I.; Rhodin, K.E.; Dechant, C.; Cui, X.; Chongsathidkiet, P.; Wilkinson, D.; Waibl-Polania, J.; Sanchez-Perez, L.; Fecci, P.E. 4-1BB Agonism Averts TIL Exhaustion and Licenses PD-1 Blockade in Glioblastoma and Other Intracranial Cancers. Clinical cancer research : an official journal of the American Association for Cancer Research 2020, 26, 1349-1358, doi:10.1158/1078-0432.CCR-19-1068.

157. Hall, M.; Liu, H.; Malafa, M.; Centeno, B.; Hodul, P.J.; Pimiento, J.; Pilon-Thomas, S.; Sarnaik, A.A. Expansion of tumor-infiltrating lymphocytes (TIL) from human pancreatic tumors. Journal for ImmunoTherapy of Cancer 2016, 4, 61, doi:10.1186/s40425-016-0164-7.

158. Liu, W.; Stachura, P.; Xu, H.C.; Bhatia, S.; Borkhardt, A.; Lang, P.A.; Pandyra, A.A. Senescent Tumor CD8(+) T Cells: Mechanisms of Induction and Challenges to Immunotherapy. Cancers (Basel) 2020, 12, 2828, doi:10.3390/cancers12102828.

159. Roninson, I.B.; Broude, E.V.; Chang, B.D. If not apoptosis, then what? Treatment-induced senescence and mitotic catastrophe in tumor cells. Drug resistance updates : reviews and commentaries in antimicrobial and anticancer chemotherapy 2001, 4, 303-313, doi:10.1054/drup.2001.0213.

160. Ewald, J.A.; Desotelle, J.A.; Wilding, G.; Jarrard, D.F. Therapy-induced senescence in cancer. J. Natl. Cancer Inst. 2010, 102, 1536-1546, doi:10.1093/jnci/djq364.

161. Campisi, J. Aging, Cellular Senescence, and Cancer. Annu. Rev. Physiol. 2013, 75, 685-705, doi:10.1146/annurevphysiol-030212-183653.

162. Coppé, J.-P.; Patil, C.K.; Rodier, F.; Sun, Y.; Muñoz, D.P.; Goldstein, J.; Nelson, P.S.; Desprez, P.-Y.; Campisi, J. Senescence-Associated Secretory Phenotypes Reveal Cell-Nonautonomous Functions of Oncogenic RAS and the p53 Tumor Suppressor. PLoS Biol. 2008, 6, e301, doi:10.1371/journal.pbio.0060301.

163. Campisi, J.; Andersen, J.; Kapahi, P.; Melov, S. Cellular senescence: a link between cancer and age-related degenerative disease? Semin. Cancer Biol. 2011, 21, 354-359, doi:10.1016/j.semcancer.2011.09.001.

164. Montes, C.L.; Chapoval, A.I.; Nelson, J.; Orhue, V.; Zhang, X.; Schulze, D.H.; Strome, S.E.; Gastman, B.R. Tumor-Induced Senescent T Cells with Suppressor Function: A Potential Form of Tumor Immune Evasion. Cancer Res. 2008, 68, 870, doi:10.1158/0008-5472.CAN-07-2282. 
165. Dossett, M.L.; Teague, R.M.; Schmitt, T.M.; Tan, X.; Cooper, L.J.; Pinzon, C.; Greenberg, P.D. Adoptive immunotherapy of disseminated leukemia with TCR-transduced, CD8+ T cells expressing a known endogenous TCR. Molecular therapy : the journal of the American Society of Gene Therapy 2009, 17, 742-749, doi:10.1038/mt.2008.300.

166. Ahmadi, M.; King, J.W.; Xue, S.A.; Voisine, C.; Holler, A.; Wright, G.P.; Waxman, J.; Morris, E.; Stauss, H.J. CD3 limits the efficacy of TCR gene therapy in vivo. Blood 2011, 118, 3528-3537, doi:10.1182/blood-2011-04346338 .

167. Legut, M.; Dolton, G.; Mian, A.A.; Ottmann, O.G.; Sewell, A.K. CRISPR-mediated TCR replacement generates superior anticancer transgenic T cells. Blood 2018, 131, 311-322, doi:10.1182/blood-2017-05-787598.

168. Morton, L.T.; Reijmers, R.M.; Wouters, A.K.; Kweekel, C.; Remst, D.F.G.; Pothast, C.R.; Falkenburg, J.H.F.; Heemskerk, M.H.M. Simultaneous Deletion of Endogenous TCR\&\#x3b1;\&\#x3b2; for TCR Gene Therapy Creates an Improved and Safe Cellular Therapeutic. Mol. Ther. 2020, 28, 64-74, doi:10.1016/j.ymthe.2019.10.001.

169. Stadtmauer, E.A.; Fraietta, J.A.; Davis, M.M.; Cohen, A.D.; Weber, K.L.; Lancaster, E.; Mangan, P.A.; Kulikovskaya, I.; Gupta, M.; Chen, F., et al. CRISPR-engineered T cells in patients with refractory cancer. Science 2020, 367, eaba7365, doi:10.1126/science.aba7365.

170. Heemskerk, M.H.M.; Hoogeboom, M.; Hagedoorn, R.; Kester, M.G.D.; Willemze, R.; Falkenburg, J.H.F. Reprogramming of Virus-specific T Cells into Leukemia-reactive T Cells Using T Cell Receptor Gene Transfer. J. Exp. Med. 2004, 199, 885-894, doi:10.1084/jem.20031110.

171. Marieke, G.; Egmond, H.M.E.v.; Helen, B.-P.; Menno, A.W.G.v.d.H.; Renate, S.H.; Michel, G.D.K.; Nikolai, S.; Roel, W.; Falkenburg, J.H.F.; Mirjam, H.M.H. Genetic engineering of virus-specific T cells with T-cell receptors recognizing minor histocompatibility antigens for clinical application. Haematologica 2008, 93, 1535-1543, doi:10.3324/haematol.13067.

172. Marleen, M.v.L.; Renate de, B.; Ellis van, L.; Pauline, M.; Inge, J.; Falkenburg, J.H.F.; Mirjam, H.M.H. A Good Manufacturing Practice procedure to engineer donor virus-specific T cells into potent anti-leukemic effector cells. Haematologica 2014, 99, 759-768, doi:10.3324/haematol.2013.093690.

173. Chapuis, A.G.; Egan, D.N.; Bar, M.; Schmitt, T.M.; McAfee, M.S.; Paulson, K.G.; Voillet, V.; Gottardo, R.; Ragnarsson, G.B.; Bleakley, M., et al. T cell receptor gene therapy targeting WT1 prevents acute myeloid leukemia relapse post-transplant. Nat. Med. 2019, 25, 1064-1072, doi:10.1038/s41591-019-0472-9.

174. $\quad$ van Loenen, M.M.; Hagedoorn, R.S.; Kester, M.G.; Hoogeboom, M.; Willemze, R.; Falkenburg, J.H.; Heemskerk, M.H. Kinetic preservation of dual specificity of coprogrammed minor histocompatibility antigenreactive virus-specific T cells. Cancer Res. 2009, 69, 2034-2041, doi:10.1158/0008-5472.can-08-2523.

175. Hart, D.P.; Xue, S.A.; Thomas, S.; Cesco-Gaspere, M.; Tranter, A.; Willcox, B.; Lee, S.P.; Steven, N.; Morris, E.C.; Stauss, H.J. Retroviral transfer of a dominant TCR prevents surface expression of a large proportion of the endogenous TCR repertoire in human T cells. Gene Ther. 2008, 15, 625-631, doi:10.1038/sj.gt.3303078.

176. Rath, J.A.; Bajwa, G.; Carreres, B.; Hoyer, E.; Gruber, I.; Martínez-Paniagua, M.A.; Yu, Y.-R.; Nouraee, N.; Sadeghi, F.; Wu, M., et al. Single-cell transcriptomics identifies multiple pathways underlying antitumor function of TCR- and CD8 $\alpha \beta$-engineered human CD4<sup $>+</$ sup $>$ T cells. Science Advances 2020, 6, eaaz7809, doi:10.1126/sciadv.aaz7809.

177. Arber, C.; Feng, X.; Abhyankar, H.; Romero, E.; Wu, M.F.; Heslop, H.E.; Barth, P.; Dotti, G.; Savoldo, B. Survivin-specific T cell receptor targets tumor but not T cells. J. Clin. Invest. 2015, 125, 157-168, doi:10.1172/jci75876. 
178. Bajwa, G.; Lanz, I.; Cardenas, M.; Brenner, M.K.; Arber, C. Transgenic CD8 $\alpha \beta$ co-receptor rescues endogenous TCR function in TCR-transgenic virus-specific T cells. Journal for ImmunoTherapy of Cancer 2020, 8, e001487, doi:10.1136/jitc-2020-001487.

179. Laugel, B.; van den Berg, H.A.; Gostick, E.; Cole, D.K.; Wooldridge, L.; Boulter, J.; Milicic, A.; Price, D.A.; Sewell, A.K. Different T Cell Receptor Affinity Thresholds and CD8 Coreceptor Dependence Govern Cytotoxic T Lymphocyte Activation and Tetramer Binding Properties. J. Biol. Chem. 2007, 282, 23799-23810, doi:10.1074/jbc.M700976200.

180. Laugel, B.; Cole, D.K.; Clement, M.; Wooldridge, L.; Price, D.A.; Sewell, A.K. The multiple roles of the CD8 coreceptor in T cell biology: opportunities for the selective modulation of self-reactive cytotoxic T cells. J. Leukoc. Biol. 2011, 90, 1089-1099, doi:10.1189/jlb.0611316.

181. Helsen, C.W.; Hammill, J.A.; Lau, V.W.C.; Mwawasi, K.A.; Afsahi, A.; Bezverbnaya, K.; Newhook, L.; Hayes, D.L.; Aarts, C.; Bojovic, B., et al. The chimeric TAC receptor co-opts the $\mathrm{T}$ cell receptor yielding robust antitumor activity without toxicity. Nature Communications 2018, 9, 3049, doi:10.1038/s41467-018-05395-y.

182. Baeuerle, P.A.; Ding, J.; Patel, E.; Thorausch, N.; Horton, H.; Gierut, J.; Scarfo, I.; Choudhary, R.; Kiner, O.; Krishnamurthy, J., et al. Synthetic TRuC receptors engaging the complete $\mathrm{T}$ cell receptor for potent anti-tumor response. Nature Communications 2019, 10, 2087, doi:10.1038/s41467-019-10097-0.

183. Gross, G.; Waks, T.; Eshhar, Z. Expression of immunoglobulin-T-cell receptor chimeric molecules as functional receptors with antibody-type specificity. Proc. Natl. Acad. Sci. U. S. A. 1989, 86, 10024-10028, doi:10.1073/pnas.86.24.10024.

184. Yao, X.R.; Flaswinkel, H.; Reth, M.; Scott, D.W. Immunoreceptor tyrosine-based activation motif is required to signal pathways of receptor-mediated growth arrest and apoptosis in murine B lymphoma cells. J. Immunol. 1995, 155, 652-661.

185. Brocker, T.; Karjalainen, K. Signals through T cell receptor-zeta chain alone are insufficient to prime resting T lymphocytes. The Journal of experimental medicine 1995, 181, 1653-1659.

186. Maher, J.; Brentjens, R.J.; Gunset, G.; Rivière, I.; Sadelain, M. Human T-lymphocyte cytotoxicity and

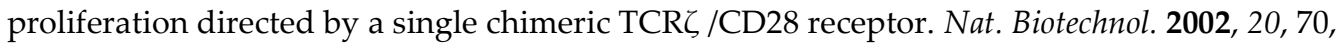
doi:10.1038/nbt0102-70.

187. Imai, C.; Mihara, K.; Andreansky, M.; Nicholson, I.C.; Pui, C.H.; Geiger, T.L.; Campana, D. Chimeric receptors with 4-1BB signaling capacity provoke potent cytotoxicity against acute lymphoblastic leukemia. Leukemia 2004, 18, 676, doi:10.1038/sj.leu.2403302.

188. Gargett, T.; Brown, M.P. The inducible caspase-9 suicide gene system as a "safety switch" to limit on-target, off-tumor toxicities of chimeric antigen receptor T cells. Front. Pharmacol. 2014, 5, 235, doi:10.3389/fphar.2014.00235.

189. Majzner, R.G.; Mackall, C.L. Tumor Antigen Escape from CAR T-cell Therapy. Cancer Discov. 2018, 8, 1219, doi:10.1158/2159-8290.CD-18-0442.

190. Long, A.H.; Haso, W.M.; Shern, J.F.; Wanhainen, K.M.; Murgai, M.; Ingaramo, M.; Smith, J.P.; Walker, A.J.; Kohler, M.E.; Venkateshwara, V.R., et al. 4-1BB costimulation ameliorates T cell exhaustion induced by tonic signaling of chimeric antigen receptors. Nat. Med. 2015, 21, 581-590, doi:10.1038/nm.3838.

191. Salter, A.I.; Ivey, R.G.; Kennedy, J.J.; Voillet, V.; Rajan, A.; Alderman, E.J.; Voytovich, U.J.; Lin, C.; Sommermeyer, D.; Liu, L., et al. Phosphoproteomic analysis of chimeric antigen receptor signaling reveals kinetic and quantitative differences that affect cell function. Science signaling 2018, 11, doi:10.1126/scisignal.aat6753. 
192. Feucht, J.; Sun, J.; Eyquem, J.; Ho, Y.-J.; Zhao, Z.; Leibold, J.; Dobrin, A.; Cabriolu, A.; Hamieh, M.; Sadelain, M. Calibration of CAR activation potential directs alternative T cell fates and therapeutic potency. Nat. Med. 2019, 25, 82-88, doi:10.1038/s41591-018-0290-5.

193. Riches, J.C.; Gribben, J.G. Understanding the immunodeficiency in chronic lymphocytic leukemia: potential clinical implications. Hematol. Oncol. Clin. North Am. 2013, 27, 207-235, doi:10.1016/j.hoc.2013.01.003.

194. te Raa, G.D.; Tonino, S.H.; Remmerswaal, E.B.; van Houte, A.J.; Koene, H.R.; van Oers, M.H.; Kater, A.P. Chronic lymphocytic leukemia specific T-cell subset alterations are clone-size dependent and not present in monoclonal B lymphocytosis. Leuk. Lymphoma 2012, 53, 2321-2325, doi:10.3109/10428194.2012.698277.

195. Tonino, S.H.; van de Berg, P.J.; Yong, S.L.; ten Berge, I.J.; Kersten, M.J.; van Lier, R.A.; van Oers, M.H.; Kater, A.P. Expansion of effector T cells associated with decreased PD-1 expression in patients with indolent B cell lymphomas and chronic lymphocytic leukemia. Leuk. Lymphoma 2012, 53, 1785-1794, doi:10.3109/10428194.2012.673224.

196. Forconi, F.; Moss, P. Perturbation of the normal immune system in patients with CLL. Blood 2015, 126, 573-581, doi:10.1182/blood-2015-03-567388.

197. Ramsay, A.G.; Johnson, A.J.; Lee, A.M.; Gorgün, G.; Le Dieu, R.; Blum, W.; Byrd, J.C.; Gribben, J.G. Chronic lymphocytic leukemia $\mathrm{T}$ cells show impaired immunological synapse formation that can be reversed with an immunomodulating drug. J. Clin. Invest. 2008, 118, 2427-2437, doi:10.1172/jci35017.

198. Riches, J.C.; Davies, J.K.; McClanahan, F.; Fatah, R.; Iqbal, S.; Agrawal, S.; Ramsay, A.G.; Gribben, J.G. T cells from CLL patients exhibit features of T-cell exhaustion but retain capacity for cytokine production. Blood 2013, 121, 1612-1621, doi:10.1182/blood-2012-09-457531.

199. Görgün, G.; Holderried, T.A.; Zahrieh, D.; Neuberg, D.; Gribben, J.G. Chronic lymphocytic leukemia cells induce changes in gene expression of CD4 and CD8 T cells. J. Clin. Invest. 2005, 115, 1797-1805, doi:10.1172/jci24176.

200. Gorgun, G.; Ramsay, A.G.; Holderried, T.A.; Zahrieh, D.; Le Dieu, R.; Liu, F.; Quackenbush, J.; Croce, C.M.; Gribben, J.G. E(mu)-TCL1 mice represent a model for immunotherapeutic reversal of chronic lymphocytic leukemia-induced T-cell dysfunction. Proc. Natl. Acad. Sci. U. S. A. 2009, 106, 6250-6255, doi:10.1073/pnas.0901166106.

201. van Bruggen, J.A.C.; Martens, A.W.J.; Fraietta, J.A.; Hofland, T.; Tonino, S.H.; Eldering, E.; Levin, M.D.; Siska, P.J.; Endstra, S.; Rathmell, J.C., et al. Chronic lymphocytic leukemia cells impair mitochondrial fitness in CD8(+) T cells and impede CAR T-cell efficacy. Blood 2019, 134, 44-58, doi:10.1182/blood.2018885863.

202. Cohen, A.D.; Garfall, A.L.; Stadtmauer, E.A.; Melenhorst, J.J.; Lacey, S.F.; Lancaster, E.; Vogl, D.T.; Weiss, B.M.; Dengel, K.; Nelson, A., et al. B cell maturation antigen-specific CAR T cells are clinically active in multiple myeloma. J. Clin. Invest. 2019, 129, 2210-2221, doi:10.1172/jci126397.

203. Fraietta, J.A.; Lacey, S.F.; Orlando, E.J.; Pruteanu-Malinici, I.; Gohil, M.; Lundh, S.; Boesteanu, A.C.; Wang, Y.; O'Connor, R.S.; Hwang, W.T., et al. Determinants of response and resistance to CD19 chimeric antigen receptor (CAR) T cell therapy of chronic lymphocytic leukemia. Nat. Med. 2018, 24, 563-571, doi:10.1038/s41591-018-0010-1.

204. Garfall, A.L.; Dancy, E.K.; Cohen, A.D.; Hwang, W.T.; Fraietta, J.A.; Davis, M.M.; Levine, B.L.; Siegel, D.L.; Stadtmauer, E.A.; Vogl, D.T., et al. T-cell phenotypes associated with effective CAR T-cell therapy in postinduction vs relapsed multiple myeloma. Blood Adv 2019, 3, 2812-2815, doi:10.1182/bloodadvances.2019000600. 
205. Ghassemi, S.; Nunez-Cruz, S.; O'Connor, R.S.; Fraietta, J.A.; Patel, P.R.; Scholler, J.; Barrett, D.M.; Lundh, S.M.; Davis, M.M.; Bedoya, F., et al. Reducing Ex Vivo Culture Improves the Antileukemic Activity of Chimeric Antigen Receptor (CAR) T Cells. Cancer Immunol Res 2018, 6, 1100-1109, doi:10.1158/2326-6066.cir-17-0405.

206. Angel, P.; Karin, M. The role of Jun, Fos and the AP-1 complex in cell-proliferation and transformation. Biochim. Biophys. Acta 1991, 1072, 129-157, doi:10.1016/0304-419x(91)90011-9.

207. Samelson, L.E. Signal transduction mediated by the T cell antigen receptor: the role of adapter proteins. Annu. Rev. Immunol. 2002, 20, 371-394, doi:10.1146/annurev.immunol.20.092601.111357.

208. Murphy, T.L.; Tussiwand, R.; Murphy, K.M. Specificity through cooperation: BATF-IRF interactions control immune-regulatory networks. Nat. Rev. Immunol. 2013, 13, 499-509, doi:10.1038/nri3470.

209. Quigley, M.; Pereyra, F.; Nilsson, B.; Porichis, F.; Fonseca, C.; Eichbaum, Q.; Julg, B.; Jesneck, J.L.; Brosnahan, K.; Imam, S., et al. Transcriptional analysis of HIV-specific CD8+ T cells shows that PD-1 inhibits T cell function by upregulating BATF. Nat. Med. 2010, 16, 1147-1151, doi:10.1038/nm.2232.

210. Lynn, R.C.; Weber, E.W.; Sotillo, E.; Gennert, D.; Xu, P.; Good, Z.; Anbunathan, H.; Lattin, J.; Jones, R.; Tieu, V., et al. c-Jun overexpression in CAR T cells induces exhaustion resistance. Nature 2019, 576, 293-300, doi:10.1038/s41586-019-1805-z.

211. Stüber, T.; Monjezi, R.; Wallstabe, L.; Kühnemundt, J.; Nietzer, S.L.; Dandekar, G.; Wöckel, A.; Einsele, H.; Wischhusen, J.; Hudecek, M. Inhibition of TGF- $\beta$-receptor signaling augments the antitumor function of ROR1-specific CAR T-cells against triple-negative breast cancer. J Immunother Cancer 2020, 8, doi:10.1136/jitc2020-000676.

212. Dahmani, A.; Delisle, J.-S. TGF- $\beta$ in T Cell Biology: Implications for Cancer Immunotherapy. Cancers (Basel) 2018, 10, doi:10.3390/cancers10060194.

213. Kloss, C.C.; Lee, J.; Zhang, A.; Chen, F.; Melenhorst, J.J.; Lacey, S.F.; Maus, M.V.; Fraietta, J.A.; Zhao, Y.; June, C.H. Dominant-Negative TGF- $\beta$ Receptor Enhances PSMA-Targeted Human CAR T Cell Proliferation And Augments Prostate Cancer Eradication. Mol. Ther. 2018, 26, 1855-1866, doi:https://doi.org/10.1016/j.ymthe.2018.05.003.

214. Ankri, C.; Shamalov, K.; Horovitz-Fried, M.; Mauer, S.; Cohen, C.J. Human T Cells Engineered To Express a Programmed Death 1/28 Costimulatory Retargeting Molecule Display Enhanced Antitumor Activity. The Journal of Immunology 2013, 10.4049/jimmunol.1203085, 1203085, doi:10.4049/jimmunol.1203085.

215. Chmielewski, M.; Abken, H. TRUCKs: the fourth generation of CARs. Expert Opin. Biol. Ther. 2015, 15, 11451154, doi:10.1517/14712598.2015.1046430.

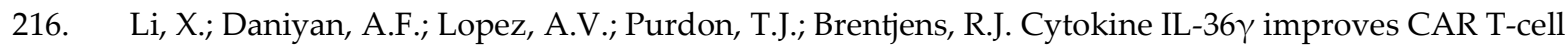
functionality and induces endogenous antitumor response. Leukemia 2020, 10.1038/s41375-020-0874-1, doi:10.1038/s41375-020-0874-1.

217. Avanzi, M.P.; Yeku, O.; Li, X.; Wijewarnasuriya, D.P.; van Leeuwen, D.G.; Cheung, K.; Park, H.; Purdon, T.J.; Daniyan, A.F.; Spitzer, M.H., et al. Engineered Tumor-Targeted T Cells Mediate Enhanced Anti-Tumor Efficacy Both Directly and through Activation of the Endogenous Immune System. Cell Rep 2018, 23, 21302141, doi:10.1016/j.celrep.2018.04.051.

218. Chmielewski, M.; Abken, H. CAR T Cells Releasing IL-18 Convert to T-Bet(high) FoxO1(low) Effectors that Exhibit Augmented Activity against Advanced Solid Tumors. Cell Rep 2017, 21, 3205-3219, doi:10.1016/j.celrep.2017.11.063. 
219. Hu, B.; Ren, J.; Luo, Y.; Keith, B.; Young, R.M.; Scholler, J.; Zhao, Y.; June, C.H. Augmentation of Antitumor Immunity by Human and Mouse CAR T Cells Secreting IL-18. Cell Rep 2017, 20, 3025-3033, doi:10.1016/j.celrep.2017.09.002.

220. Yeku, O.O.; Purdon, T.J.; Koneru, M.; Spriggs, D.; Brentjens, R.J. Armored CAR T cells enhance antitumor efficacy and overcome the tumor microenvironment. Sci. Rep. 2017, 7, 10541, doi:10.1038/s41598-017-10940-8.

221. Zhang, L.; Morgan, R.A.; Beane, J.D.; Zheng, Z.; Dudley, M.E.; Kassim, S.H.; Nahvi, A.V.; Ngo, L.T.; Sherry, R.M.; Phan, G.Q., et al. Tumor-infiltrating lymphocytes genetically engineered with an inducible gene encoding interleukin-12 for the immunotherapy of metastatic melanoma. Clin. Cancer. Res. 2015, 21, 2278-2288, doi:10.1158/1078-0432.ccr-14-2085.

222. Zhang, L.; Davies, J.S.; Serna, C.; Yu, Z.; Restifo, N.P.; Rosenberg, S.A.; Morgan, R.A.; Hinrichs, C.S. Enhanced efficacy and limited systemic cytokine exposure with membrane-anchored interleukin-12 T-cell therapy in murine tumor models. Journal for ImmunoTherapy of Cancer 2020, 8, e000210, doi:10.1136/jitc-2019-000210.

223. Lapteva, N.; Gilbert, M.; Diaconu, I.; Rollins, L.A.; Al-Sabbagh, M.; Naik, S.; Krance, R.A.; Tripic, T.; Hiregange, M.; Raghavan, D., et al. T-Cell Receptor Stimulation Enhances the Expansion and Function of CD19 Chimeric Antigen Receptor-Expressing T Cells. Clin. Cancer. Res. 2019, 25, 7340, doi:10.1158/10780432.CCR-18-3199.

224. von Kalle, C.; Deichmann, A.; Schmidt, M. Vector Integration and Tumorigenesis. Hum. Gene Ther. 2014, 25, 475-481, doi:10.1089/hum.2014.2525.

225. Fraietta, J.A.; Nobles, C.L.; Sammons, M.A.; Lundh, S.; Carty, S.A.; Reich, T.J.; Cogdill, A.P.; Morrissette, J.J.D.; DeNizio, J.E.; Reddy, S., et al. Disruption of TET2 promotes the therapeutic efficacy of CD19-targeted T cells. Nature 2018, 558, 307-312, doi:10.1038/s41586-018-0178-z.

226. Schmitz, M.L. Activation of T cells: releasing the brakes by proteolytic elimination of Cbl-b. Science signaling 2009, 2, pe38, doi:10.1126/scisignal.276pe38.

227. Shah, N.N.; Qin, H.; Yates, B.; Su, L.; Shalabi, H.; Raffeld, M.; Ahlman, M.A.; Stetler-Stevenson, M.; Yuan, C.; Guo, S., et al. Clonal expansion of CAR T cells harboring lentivector integration in the CBL gene following anti-CD22 CAR T-cell therapy. Blood Adv 2019, 3, 2317-2322, doi:10.1182/bloodadvances.2019000219.

228. Eyquem, J.; Mansilla-Soto, J.; Giavridis, T.; van der Stegen, S.J.C.; Hamieh, M.; Cunanan, K.M.; Odak, A.; Gönen, M.; Sadelain, M. Targeting a CAR to the TRAC locus with CRISPR/Cas9 enhances tumour rejection. Nature 2017, 543, 113-117, doi:10.1038/nature21405.

229. Nianias, A.; Themeli, M. Induced Pluripotent Stem Cell (iPSC)-Derived Lymphocytes for Adoptive Cell Immunotherapy: Recent Advances and Challenges. Curr. Hematol. Malig. Rep. 2019, 14, 261-268, doi:10.1007/s11899-019-00528-6.

230. Themeli, M.; Kloss, C.C.; Ciriello, G.; Fedorov, V.D.; Perna, F.; Gonen, M.; Sadelain, M. Generation of tumortargeted human $\mathrm{T}$ lymphocytes from induced pluripotent stem cells for cancer therapy. Nat. Biotechnol. 2013, 31, 928-933, doi:10.1038/nbt.2678.

231. Xie, G.; Dong, H.; Liang, Y.; Ham, J.D.; Rizwan, R.; Chen, J. CAR-NK cells: A promising cellular immunotherapy for cancer. EBioMedicine 2020, 59, doi:10.1016/j.ebiom.2020.102975.

232. Zhang, Y.; Wallace, D.L.; de Lara, C.M.; Ghattas, H.; Asquith, B.; Worth, A.; Griffin, G.E.; Taylor, G.P.; Tough, D.F.; Beverley, P.C., et al. In vivo kinetics of human natural killer cells: the effects of ageing and acute and chronic viral infection. Immunology 2007, 121, 258-265, doi:10.1111/j.1365-2567.2007.02573.x.

233. Klingemann, H. Are natural killer cells superior CAR drivers? Oncoimmunology 2014, 3, e28147, doi:10.4161/onci.28147. 
234. Oei, V.Y.S.; Siernicka, M.; Graczyk-Jarzynka, A.; Hoel, H.J.; Yang, W.; Palacios, D.; Almåsbak, H.; Bajor, M.; Clement, D.; Brandt, L., et al. Intrinsic Functional Potential of NK-Cell Subsets Constrains Retargeting Driven by Chimeric Antigen Receptors. Cancer Immunol Res 2018, 6, 467-480, doi:10.1158/2326-6066.cir-17-0207.

235. Ueda, T.; Kumagai, A.; Iriguchi, S.; Yasui, Y.; Miyasaka, T.; Nakagoshi, K.; Nakane, K.; Saito, K.; Takahashi, M.; Sasaki, A., et al. Non-clinical efficacy, safety and stable clinical cell processing of induced pluripotent stem cell-derived anti-glypican-3 chimeric antigen receptor-expressing natural killer/innate lymphoid cells. Cancer Sci. 2020, 111, 1478-1490, doi:https://doi.org/10.1111/cas.14374.

236. Yang, Y.; Badeti, S.; Tseng, H.-c.; Ma, M.T.; Liu, T.; Jiang, J.-G.; Liu, C.; Liu, D. Superior Expansion and Cytotoxicity of Human Primary NK and CAR-NK Cells from Various Sources via Enriched Metabolic Pathways. Molecular Therapy - Methods E Clinical Development 2020, 18, 428-445, doi:https://doi.org/10.1016/j.omtm.2020.06.014.

237. Liu, E.; Marin, D.; Banerjee, P.; Macapinlac, H.A.; Thompson, P.; Basar, R.; Nassif Kerbauy, L.; Overman, B.; Thall, P.; Kaplan, M., et al. Use of CAR-Transduced Natural Killer Cells in CD19-Positive Lymphoid Tumors. N. Engl. J. Med. 2020, 382, 545-553, doi:10.1056/NEJMoa1910607.

238. Klichinsky, M.; Ruella, M.; Shestova, O.; Lu, X.M.; Best, A.; Zeeman, M.; Schmierer, M.; Gabrusiewicz, K.; Anderson, N.R.; Petty, N.E., et al. Human chimeric antigen receptor macrophages for cancer immunotherapy. Nat. Biotechnol. 2020, 38, 947-953, doi:10.1038/s41587-020-0462-y. 